\title{
İslam'ın Yerelleşmesi ve Küreselleşmesi: Çin İslamı Örneği
}

\author{
The Localization and Globalization of Islam: The Case of Chinese Islam
}

\author{
Chih-Hui Chiu* ${ }^{*}$
}

Öz

İslam, ilk girişinden itibaren bugüne kadar kesintisiz bir şekilde Çin'deki varlığını devam ettirmiştir. Bilindiği üzere, Çin çok eski ve kendisine has bir kültürel sisteme sahiptir. Bu sistemin özelliklerinden biri de, dışarıdan gelen kültürleri kendi içinde eritme yeteneğidir. Bunlara rağmen İslam, Çin kültürüyle çevrili ortamda yine de ayakta kalabilmiştir. Bunun nedenlerinden birisi, İslam'ın Çinlileşmesidir (yerelleşmesidir). Bu süreç sayesinde İslam asimile olmaksızın Çin kültürüyle bütünleşebilmiş ve onun siyasi, ekonomik ve toplumsal arkaplanına kendisini uydurabilmiştir. Öte yandan, Çin İslamı'nın İslam dünyasının geri kalanıyla irtibatını sürdürmesi anlamındaki küreselleşmesi de yerelleşmeyle aynı öneme sahiptir. Çin İmparatorluğunun son dönemlerinde meydana gelen İslami ihya ve ıslah hareketleri ile Çinli Müslümanların dini bilincinin yeniden uyanışı, İslam'ın küreselleşmesi bağlamında düşünülmesi gereken bir durumdur. Çünkü Çinli Müslümanlar İslam dünyasıyla iletişim kurarak kendi inançlarını sorgulamaya ve duruma uygun bir şekilde yorumlamaya/anlamaya başlamışlardır. Dolayısıyla, Çin İslamı önemli derecede yerelleştiği halde, daima İslami esaslara sımsıkı tutunmuştur. Bu anlamda küreselleşmenin Çin İslamı́nın İslami prensiplerini muhafaza etmesine katkıda bulunduğu söylenebilir. Bu makalede, İslam'ın Konfüçyüsçülük'le bütünleşmesi ve bu bütünleşme sürecinin asimilasyona dönmesini önleyen ihya ve ıslah hareketlerinin ortaya çıkışı Çin İslam tarihinde yaşanan önemli olaylar ışığında yerelleşme ve küreselleşmenin, İslam'ın Çin'deki gelişimi üzerindeki etkileri tartışılacaktır.

\section{Anahtar Kelimeler}

Çin İslamı, Çinli Müslümanlar (Huiler), Çin medrese eğitim sistemi, Konfüçyüsçü-Müslümanlık (Hui-Ru), Çin İslami ihya ve ıslah hareketleri

\begin{abstract}
Islam has been existing for thousands of years since arriving in China until today. As it is known, there is a very old and unique culture system in China. In addition to these different cultural structures, Chinese culture is characterized by absorbing foreign cultures within itself. Despite all of this, Islam still survived in an environment surrounding by Chinese culture. One of the reasons for this is the sinicization (localization) of Islam. Thanks to this process, Islam could integrate but without being assimilated into Chinese culture, and adjust herself to China's political, economic and social backgrounds. On the other hand, globalization, which maintains connection between Chinese Islam and Islamic world, is as important as localization throughout the history of Chinese Islam. Islamic revival and reform movements occurred in the late China Empire and the awakening of Chinese Muslims' religious awarness, should be considered in the context of the globalization of Islam. It is because of the establishment of contact between Chinese Muslims and Islamic World that they started to reexamine their own faith. Therefore, Chinese Islam always clings to Islamic tenets in spite of being localized substantially. In this sense, it is possible to say that globalization help Chinese Islam maintain her İslamic principles. In this paper, the influence of localization and globalization on the development of Chinese Islam will be examined in the light of important events in history of Chinese Islam, such as the integration of Islamic and Confucian thoughts and the occurrence of Chinese Islamic revival and reform movements, which prevented integration process from transforming into assimilation.
\end{abstract}

\section{Keywords}

Chinese Islam, Chinese Muslim (Hui people), Chinese madrasa education system, Confucian-Mohammadanism (Hui-Ru), Chinese Islamic revival and reform movements

\footnotetext{
* Sorumlu Yazar: Chih-Hui Chiu (Doktora Öğrencisi), Sakarya Üniversitesi, Sosyal Bilimler Enstitüsü, Felsefe ve Din Bilimleri Flesefe ve Din Bilimleri Anabilim Dalı, Taipei, Taiwan. E-posta: urflea@hotmail.com ORCID: 0000-0002-6601-3438
}

Attf: Chih-Hui Chiu, “íslam’ın Yerelleşmesi ve Küreselleşmesi: Çin İslamı Örneği.” darulfunun ilahiyat 31, 2 (2020): $457-484$. https://doi.org/10.26650/di.2020.31.2.0006 


\section{Extended Summary}

The history of Chinese Islam can be traced back to the early era of Islam. As early as the Tang dynasty, Islam has been introduced to China. As it is known, Chinese culture is totally different from Islamic culture and can absorb foreign cultures into itself. Nonetheless, since arriving in China, Islam has been surviving in an environment surrounding by dominant Chinese culture for thousands of years. The reason for this is the localization and globalization of Islam.

The purpose of this paper is to argue how the localization and globalization of Islam asserted influence on the development of Chinese Islam. In the first part of this paper, the beginning of the localization of Islam will be dealt with. As many historians shown, this process was triggered by the policies of sinicization during Ming dynasty. Due to these policies, Muslims abandoned their original cultural traits and started to accept Chinese culture. These adjustments can be considered the beginning of the localization of Islam. Yet, this process is confined to material aspects.

In contrast to material localization, intellectual localization of Islam will be examined in the second part of this paper. Through the process of localization, Chinese Muslims' faith was weakened significantly. In this context, Chinese Muslim scholars launched series of activities intending to keep Chinese Muslims holding true Islamic faith and to protect Islam against assailments from Chinese Confucian literati. These activities can be principally represented in establishing Chinese madrasa education system and writing Chinese Islamic literature.

The intellectual localization of Islam substantially influenced the development of Islam in China. First of all, through the establishment of Chinese madrasa education system, Chinese Muslims could pass down their religious knowledge to the younger generation. In addition, a special kind of textbooks and lingua franca has been invented. They are a hybrid of Chinese, Arabic and Persian language, teaching grammar, language skills and Islamic knowledge. Secondly, because of the educatedness of Chinese Muslim scholars in the traditional Confucian education system, Islamic and Confucian thoughts was significantly integrated through the Chinese Islamic literature they composed. They could not only interpret Islamic thoughts with Confucianism but also rethink the relationship between these two philosophy. In other words, their works could further integrate Islamic and Confucian thoughts on the one hand, but keep Islamic thoughts free from influences of non-Islamic thoughts on the other. In brief, these activities have shaped the form of Chinese Islam which demonstrates Confucian and İslamic cultural traits at the same time.

The impacts of global Islam on Chinese Islam will be argued in the third part of this paper. Wahhabism has been introduced to China through hajj since the late Qing dynasty. With its significant influence, two Islamic revival and reform movements were 
launched in the Northwest of China: Yihewani (Ikhwan) and Sailaifengye (Salafi) (later on separated from Yihewani). In the sense of doctrines and religious thoughts, both movements represented a salafi position in general. They put emphasis on turning back to the pure Islam, advocated the importance of Holy Texts and criticized religious practices involving Chinese customs and Sufic practices. However, they are different from each other in detailed matters related to religious practices.

Even though Yihewani and Sailaifengye were inspired by Wahhabbism, unlike other salafi movements, they never become political ideology dominant in China. The reason is that the founders of these movements modified their thoughts recieved from Wahhabbism according to the different contexts of China. As a result they only focused on reforming Chinese Muslims' religious practices and raising their religious awareness. In this sense, localization could be considered the otherside of globalization.

In conclusion, the viewpoint of that the localization and globalization of Islam is a dialectic process will be put forward. According to this viewpoint, the development of Chinese Islam is pushing by the interaction of these two counterparts. Both of them help Islam integrate with local culture but keep Chinese Islam attached to Islamic principles. 


\section{İslam'ın Yerelleşmesi ve Küreselleşmesi: Çin İslamı Örneği}

Çin kadim ve kendisine has bir kültürel sisteme sahiptir. Bu sistemin özelliklerinden biri de dışarıdan gelen kültürleri kendi içinde eritme/asimile etmesidir. Çin kültürünün bu özelliğine rağmen İslam Çin'e geldikten sonra asimile olup ortadan kaybolmamıştır. Tam aksine Çin kültürüyle etkileşim içine girmiş ve bunun sonucu olarak da yerelleşmiştir. Bu sayede İslam Çin kültürüyle çevirili ortamda ayakta kalabilmiş; ayrıca farklı düşünceler, dünya görüşleri ve örfleriyle de onu zenginleştirmiştir.

Çin İslam ${ }^{1}$ tarihinde küreselleşme de yerelleşmeyle aynı öneme sahiptir. Çin İslamı yerelleşmeyle Çin kültürüyle; küreselleşmeyle de İslam dünyasıyla irtibatını

1 Çin İslamı altında iki kültürel sistem bulunmaktadır. Onlardan birisi Huiler, Bao'anlar, Salarlar ve Dongxianglar olarak Çin kültürü tarafından çok etkilenen ve Çin kültürel özellikleri gösteren dört etnik azınlık grubundan oluşmaktadır. Diğeri ise çoğunluğu Doğu Türkistan'da (Xinjiang'da) yaşayan Uygurlar, Kazaklar, Kırgızlar Özbekler, Tacikler ve Tartarlar olarak altı etnik azınlık grubundan oluşmaktadır. Bu gruplar Çin kültüründen ziyade daha çok Orta Asya'daki Türk kültürü tarafından etkilenmekte ve Türk milletiyle arasında kan akrabalığı bulunmaktadır. $\mathrm{Bu}$ on etnik grubun teşkil ettiği kültürel bütüne "Çin İslamı" ve etnik grup mensuplarına da "Çinli Müslümanlar" denilebilir. Öyleyse bu iki sözcük genel anlamda, "Çin sınırları içinde bulunan İslami kültürler" ve "bu on etnik grup mensupları ve Çin vatandaşları olan Müslümanların bütünü”nü ifade etmektedir. Bu anlamda bu iki sözcük, ülke sınırı ve vatandaşlık anlamı temelinde kurulduğu için, siyasi bir anlam taşımaktadır Bununla birlikte bu makalede kullanılan "Çin İslamı" ve "Çinli Müslümanlar" sözcügünün, siyasi olmaktan daha ziyade kültürel bir anlam taşıdığını söylemek gerekir. Bir diğer deyişle Çin İslamı sözcügüyle Çin kültürel özellikleri gösteren ve yerelleşmiş olan İslam tarzı kastedilmektedir. Çinli Müslümanlar sözcügüuyle ise Çin kültürü tarafından etkilenen etnik grupların mensupları ifade edilmektedir. Bu durum "Çin İslamı," "Çin tarzı İslam" olarak da ifade edilebilir. Buna rağmen makalede daha kısa ve basit olduğu "Çin İslamı" tercih edilmektedir. Buna karşılıklı olarak da "Çinli Müslümanlar" kullanılmaktadır. Nitekim Batı akademik camiasında ilgili çalışmaların büyük kısmı, kültürel bir yaklaşımla yerelleşmiş (Çinlileşmiş) İslam'ı incelemektedir. Dolayısıyla bu iki sözcüğün net bir anlam ifade edebileceğini söylemek yerinde olacaktır. Bkz Elvida Ünal, "Çin Tarzı İslam: Konfüçyanist Müslümanlık (Hui-Ru),” TYB Akademi 20 (Eylül 2017), erişim 02.06.2020. http://www.tyb.org.tr/elvida-unal-cin-tarzi-islam-konfucyanist-muslumanlik-hui-ru-31491h. htm. Shou-Jiang Mi and Jia You, Çin Íslamı'nın Kısa Tarihi (中國伊斯蘭教簡史) (Beijing: Zongjiao Wenhua Chubanshe, 2000), 132-136. Ling-Gui Wang, Çin İslam Tarihi (中國伊斯 蘭教史) (Beijing: Zhongguo Youyi Chuban Gongsi, 2014), 249-269. Qi-cheng Ma \& Hong Ding, Çin Íslamı'nın Kültürü Kategorisi ve Etnik Özellikleri (中國伊斯蘭文化類型與民族特 色) (Beijing: Zhongyang Minzu Daxue Chubanshe, 1991), 118-163. Raphael Israeli, Islam in China: Religion, Ethnicity, Culture, and Politics (Oxford: Lexintong Books, 2002). Michael Dillon, China's Muslim Hui Community: Migration, Settlement and Sects (Richmond Surrey: Curzon Press, 1999). Jonathan Lipman ed., Islamic Thought in China: Sino-Muslim Intellectual Evolution from the 17th to the 21st Century (Edinburgh: Edinburgh University Press, 2016). Alexander Blair Stewart, Chinese Muslims and the Global Ummah: Islamic Revival and Ethnic Identity among the Hui of Qinghai Province (New York: Routledge, 2017). Dru C. Gladney, Muslim Chinese: Ethnic Nationalism in the Peopel's Republic of China (Cambridge: Havard University Council on East Asian Studies, 1991). 
sürdürmektedir. Ming (1368-1644) ve Qing (1644/5-1911/2) hanedanlığı döneminde ortaya çıkan İslami ihya ve sslah hareketleri, Çinli âlimlerin hac sırasında aldıkları ilhamdan kaynaklanmıştır. Modern dönemler itibarıyla, Hui etnik grubu içinde İslam inancına önem verilmekte ve dini kimlik yeniden ön plana çıkmaktadır. Bütün bu olayların, İslam'ın küreselleşmesinin ürünleri olarak değerlendirilmesi mümkündür. Çünkü Çinli Müslümanlar İslam dünyasıyla iletişim kurarak kendi inançlarını sorgulamaya ve yeniden anlandırmaya başlamışlardır. Dolayısıyla, Çin İslamı önemli derecede yerelleştiği halde, daima İslami esaslara sımsıkı bağlı kalmaya çalışmıştır.

Çin İslamı, özellikle Konfüçyüsçülükle bütünleşmiştir. Konfüçyanist Müslümanlık (Huiru, 回儒), Türkiye akademik camiasında oldukça yeni bir araştırma sahasıdır. ${ }^{2}$ Buna rağmen bu alanda kayda değer çalışmaların yapıldığının da zikredilmesi gerekmektedir. "Çin Tarzı İslam: Konfüçyanist Müslümanlık (Hui-Ru)"; "Çin’de İlk İslami Entelektüel Çaba ve Konfüçyanist Müslümanlar (Hui-Ru)" ve "Klasik İslam Eserlerinin Çince'ye Tercüme Faaliyetlerinin Çin'de İslamiyet' in Gelişimine Katkısı" makaleleri yerelleşmiş Çinli Müslüman âlimlerin başlattıkları faaliyetlere odaklanmıştır. Bu çalışmalarda Çin medrese eğitim sisteminin kuruluşu, İslami klasik eserlerin Çinceye çevrilmesi ve Konfüçyüsçü düşüncelerle İslam'ı açıklama şeklindeki üç entelektüel faaliyetin tarihsel, toplumsal ve dinsel arkaplanıyla ilgili bilgiler sunulmaktadır. Bu araştırmacılar söz konusu faaliyetlerin, Konfüçyanist Müslüman âlimlerin ve Çin İslamı'na özel bir kelam sisteminin ortaya çıkışına ve bunun Çin İslam tarihindeki önemine ve katkısına işaret etmişlerdir. Bu çalışmalar makalenin ikinci kısmı için İslam'ın yerelleşmesi konusunda genel bilgiler sunarak 1ş1k tutmuştur. ${ }^{3}$

Söz konusu entelektüel faaliyetle ilgili temel bilgilerin yanı sıra spesifik konular üzerinde yürütülen araştırmalar da mevcuttur. Örneğin Çinli Müslüman âlim Wang Daiyu'nün Çin İslam Tarihindeki Yeri ve Önemi adlı doktora tezinde, İslam'ın Çin'e gelişi ve burada yaşanan gelişmeler anlatıldıktan sonra Wang Dai-Yu'nün önemli eserleri ve felsefi düşünceleri üzerinde durulmuştur. Çinli Müslüman âlimlerden ve Çin İslam anlayışını oluşumuna katkıda bulunan Wang Dai-Yu'nün düşüncelerini anlamakta faydalı olan çalışmasının sonunda yazar, Wang'ın Çin ve İslam medeniyeti arasında akademik bir köprü kurduğunu ve bu köprünün

2 Ünal, "Çin Tarzı İslam: Konfüçyanist Müslümanlık (Hui-Ru).” Esra Çifçi, "Çin'de İlk İslami Entelektüel Çaba ve Konfüçyanist Müslümanlar (Hui-Ru)," II. Türkiye Lisansüstü Çalışmalar Kongresi Bildiriler Kitabl - IV (6-8 May1s 2013, Bursa), 866.

3 Ünal, “Çin Tarzı İslam: Konfüçyanist Müslümanlık (Hui-Ru).” Çifçi, “Çin’de İlk İslami Entelektüel Çaba ve Konfüçyanist Müslümanlar (Hui-Ru).” 
üzerinden yüzyılların bilgi ve birikiminin geçmesini sağladığı sonucuna ulaşmıştır. ${ }^{4}$ Çin Kaynaklarına Göre Mançu (Çing) Handanı Döneminde (1644-1911), Çin'de İslamiyet çalışmasında ise, Çin İslam tarihine kısa bir şekilde değinildikten sonra Qing hanedanlığı dönemindeki Müslümanların hayatlarının dinsel, siyasal, iktisadi ve eğitimsel vs. gibi çeşitli yönlerine dair kapsamlı bilgiler sunulmuştur. İslam'ın zihinsel yerelleşme sürecine yol açan entelektüel faaliyetlerin yanı sıra Qing hanedanlığı döneminde ortaya çıkan İslami ihya ve 1slah hareketlerinden de bahsedilmiştir. ${ }^{5} \mathrm{Bu}$ nedenle Makalenin üçüncü kısmında tartışılan konuyla ilgili bilgiler de bu çalışmada bulunabilir.

Batı akademik camiası ise Çin İslamı'yla ilgili araştırmalar bakımından oldukça zengindir. İslam in China: A Neglected Problem adlı eserde Çin İslam tarihinin yanı sıra yazarının Çin'deki gözlemleri de sunulmaktadır. ${ }^{6}$ Eserin konumuzla ilişkisi oldukça sınırlı olduğu halde, o dönemdeki İslam ve Müslümanları anlamak için faydadan hali değildir. Ancak yazar eseri, Çin'de icra edilecek misyonerlik sırasında kullanılmak maksadıyla yazdığı için, sunduğu bilgilerin kullanılmasında dikkatli olunması gerekmektedir. Bir diğer çalışma olan Islam in China: Religion, Ethnicity, Culture, and Politics, Islam in China: Key Papers, ve China's Muslim Hui Community: Migration, Settlement and Sects ise, İslam'ın yerelleşmesiyle ilgili bilgiler içermektedir. ${ }^{7}$ Ayrıca Çin'in yakın tarihinde ortaya çıkan İslami ihya ve 1slah hareketleri üzerine bir çalışma olan Chinese Muslims and the Global Ummah: Islamic Revival and Ethnic Identity among the Hui of Qinghai Province, makalenin üçüncü kısmı için oldukça faydalı bilgiler içermektedir. Yine bu eserde Yihewani (Ikhwan) ve Salaifengye'nin (Selefilik) yanı sıra Tebliği Cemaati ve bu grupların Müslümanların kimlikleri üzerindeki tesirleri de ele alınmaktadır. ${ }^{8}$ Son olarak ele aldığımız konunun ayrıntılarını derinlemesine inceleyen çalışmalar da zikredilebilir. Örneğin Muslim Sanzijing: Shifts and Continuities in the Definition of Islam in China (1710-2010) adlı çalışmada Liu Zhi'nın İslam Dünyasının

4 Ertuğrul Ceylan, Çinli Müslüman âlim Wang Daiyu'nün Çin İslam Tarihindeki Yeri ve Önemi, yayımlanmamış doktora tezi, Ankara: (Ankara Üniversitesi, 2019).

5 Wu Maerjiang, Çin Kaynaklarına Göre Mançu (Çing) Handanı Döneminde (1644-1911), Çin'de Íslamiyet, yayımlanmamış doktora tezi, (İstanbul: Marmara Üniversitesi, 2018).

6 Marshall Broomhall, Islam in China: A Neglected Problem (London: China Inland Mission, 1910).

7 Raphael Israeli, Islam in China: Religion, Ethnicity, Culture, and Politics (Oxford: Lexintong Books, 2002). Michael Dillon ed., Islam in China: Key Papers 2 vol., (Folkstone: Global Oriental, 2009). Michael Dillon, China's Muslim Hui Community: Migration, Settlement and Sects (Richmond Surrey: Curzon Press, 1999).

8 Alexander Blair Stewart, Chinese Muslims and the Global Ummah: Islamic Revival and Ethnic Identity among the Hui of Qinghai Province (New York: Routledge, 2017). 
Ayinleri (Tianfang Dianli, 天方典禮) eserinde kaynaklanan ve Müslümanlar1 eğitmede kullanılan özel bir edebi türe (sanzijing, 三字經, üç karakterli şiir) odaklanarak onun farklı dönemlerdeki biçimleri; fikıh, ayinler ve Müslümanların düşünceleri üzerindeki etkileri ele alınmıştır. ${ }^{9}$ The Dao of Muhammad: A Cultural History of Muslims in Late Imperial China çalışması ise Çin' in doğusunda bulunan Müslümanlar üzerine odaklanarak Çince dini kitaplarının ortaya çıkışı, Çinli Müslüman âlimlerin oluşturdukları entelektüel ağlar ele alınmaktadır. Bu eserde Çin İslami bilgilerinin âlimler arasında yayılışı, nesilden nesle (silsile) aktarılmasının, bilgilerin içerdiği mesajların kapsamlı bir şekilde tartışıldığını ve Çin İslamı`nın entelektüel hayatında erken dönemden modern döneme kadar yaşanan gelişmeleri sunduğunu söylemek mümkündür. ${ }^{10}$ Makale derlemesi şeklinde yayımlanan Islamic Thought in China: Sino-Muslim Intellectual Evolution from the 17th to the 21st Century adlı eser ise, ilk dönemden günümüze kadar Çinli Müslümanların düşüncelerini araştıran bir dizi makaleyi içermektedir. Bu makalelerde belli Çinli Müslüman âlimlerin düşüncelerinin incelenmesinin yanı sıra Çince dini kitaplarda bulunan özel kavramlar ve belli dönemlerde dikkatleri çeken entelektüel faaliyetler de ele alınmaktadır. ${ }^{11} \mathrm{Bu}$ türden araştırmalar çok spesifik oldukları için bu makale onlardan pek faydalanamamıştır. Buna rağmen ele aldığımız konuyla ilgili ileri araştırmalar için faydalı kaynaklardır.

Çin'de konumuzla ilgili çalışmaların sayısı oldukça fazladır. Genel olarak Çin İslam tarihini inceleyen her eserde İslam'ın yerelleşmesi, Konfüçyüsçü düşüncelerle bütünleşmesiyle ihya ve 1 slah hareketlerinin ortaya çıkışından bahsedilmektedir. ${ }^{12}$ Bunlar dışında Jin Yi-Jiu'nun çalışmaları zikre değerdir. Jin en önemli Çinli Müslüman âlimlerden olan Wang Dai-Yu ve Liu Zhi üzerinde birer çalışma yayınlamıştır. Bu eserlerde iki âlimin hayatı, düşünceleri, eserleri ve Çin İslamı'ndaki önemiyle ilgili bilgiler ayrıntılı bir şekilde aktarılmaktadır. Âlimlerin hayatının da

9 Roberta Tontini, Muslim Sanzijing: Shifts and Continuities in the Definition of Islam in China (1710-2010) (Leiden: Brill, 2016).

10 Zvi Ben-Dor Benite, The Dao of Muhammad: A Cultural History of Muslims in Late Imperial China (London: Havard University Asia Center, 2005).

11 Jonathan Lipman ed., Islamic Thought in China: Sino-Muslim Intellectual Evolution from the 17th to the 21st Century (Edinburgh: Edinburgh University Press, 2016).

12 Mi and You, Çin İslamı'nın Kısa Tarihi, 150-177. Wang, Çin İslam Tarihi, 206-215. Gui-Ping Yang and Xiao-Ying Ma, Íslam Uzun Vadeli Muhteşemdir: Çin Íslamı (清真長明: 中國伊斯蘭 教) (Beijing: Zongjiao Wenhua Chubanshe, 2007), 139-141, 171-208. Çin İslam Derneği ed., An Overview of İslam in China (中國伊斯蘭教簡志) (Beijing: Zongjiao Wenhua Chubanshe, 2013), 72-73, 75-76. Chang-Kuan Lin, Çin İslam'ının Gelişmeleri ve Hareketleri (中國回教 之發展及其運動) (Taipei: Zhonghua Mingguo Alabo Wenhua Jingji Xiehui, 1996), 25-76. Ma \& Ding, Çin İslamı'nın Kültürü Kategorisi ve Etnik Özellikleri, 62-74. 
incelenmesi, Çinli Müslüman âlimlerin başlattıkları entelektüel faaliyetlerin tarihsel arkaplanını anlamaya ışık tutmaktadır. ${ }^{13}$ Jin' in diğer eseri Çin'deki Tasavvuf üzerine kalem alınmıştır. Bu eserde Tasavvufun Çin'e girişi, Çin'deki yayılışı ve çeşitli tarikatların kuruluşu gibi konuların yanı sıra Tasavvuf düşüncesinin Çin medrese eğitim sistemi ve Çinli Müslüman âlimler üzerindeki etkileri de ele alınmıştır. ${ }^{14}$ Jin' in çalışmalarının, bu makalenin konusuyla çok yakından ilgili bilgiler sunarak zihinsel bir zemin oluşturması bakımından değerli ve önemli olduğunu söylemek gerekir.

Söz konusu çalışmaların çoğu, yerelleşme süreci, İslami ihya ve sslah hareketlerinin ortaya çıkışı ve İslam'ı Konfüçyüsçü düşüncelerle açılama gibi statik olaylara odaklanmakta; ve bu olaylar nedeniyle Çin İslamı'nın ortaya çıktığına, veya bir diğer deyişle, İslam'ın yerelleşmesinin tamamlandığına işaret etmişlerdir. Ancak Çin İslamı'nın asimile olmaktan kaçınarak günümüze kadar ayakta kalabilmesinin gerçek sebebinin, statik olaylardan ziyade yerelleşmeden ihya ve sslaha geçen dinamik bir süreç olduğunu söylemek gerekir. Dolayısıyla bu makalede statik olaylardan ziyade İslam'ın Çin' deki gelişiminin dinamik süreci daha çok ön plana çıkarılmaya çalışılacaktır. Bu bağlamda olmak üzere söz konusu sürecin açılanması ve tartışılması bu makalenin asıl amaçları arasında yer alacaktır.

İslam'ın yerelleşmesi ve küreselleşmesi, Çin İslamı'nın ayakta kalmasında hayati bir rol oynamaktadır. İslam'ın Çin'e gelişinden itibaren bu iki süreç birbirleriyle etkileşerek Çin İslam tarihini oluşturmuştur. Bu nedenle İslam'ın yerelleşmesi ve küreselleşmesinin, Çin İslamı'nı anlamak için özel bir yaklaşım sunduğunu söylemek yerindedir. Bu makalede, İslam'ın Konfüçyüsçülük'le bütünleşmesi ve bu bütünleşme sürecinin asimilasyona dönmesini önleyen ihya ve sslah hareketlerinin ortaya çıkışı, Çin İslam tarihinde yaşanan önemli olaylar ışığında yerelleşme ve küreselleşmenin İslam'ın Çin'deki gelişimi üzerindeki etkileri tartışılacaktır.

\section{İslam'ın Yerelleşmesinin Başlaması}

İslam'ın yerelleşmesi, Ming hanedanlığı'nın son dönemlerinde başlamıştır. Meşhur Çinli Müslüman tarihçi Bai Shou-Yi (ö. 1420/2000, 白壽彝), Çin İslam tarihini kökleşme, gelişme ve yeni çağ olmak üzere üç dönem ayırmıştır. ${ }^{15}$ İslam'ın

13 Yi-Jiu Jin, Wang Dai-Yu’nün Düşüncelerinin İncelenmesi (王岱輿思想研究) (Beijing: Minzu Chubanshe, 2008). Yi-Jiu Jin, Çin İslamı'nın Gizeminin Keşfi: Liu Zhi İncelemesi (中國伊斯 蘭探秘: 劉智研究) (Beijing: Zhongguo Renmin Daxue Chubanshe, 2010).

14 Yi-Jiu Jin, Sufism in China (蘇菲主義在中國) (Beijing: Social Sciences Academic Press, 2013).

15 Bkz. Shou-Yi Bai, Çin İslamı'nın Küçük Tarihi (中國回教小史) (Ningxia: Ningxia Renmin Chubanshe, 2000), 44. 
yerelleşmesi, bu sınıflamanın ikinci dönemine denk gelmektedir. Bu bakımdan, yerelleşme sürecinin, İslam'ın Çin' deki gelişmesi, ayakta kalması ve Çin İslamı'nın oluşumu için hayati bir rol oynadığını söylemek yerinde olacaktır.

İslam'ın yerelleşmesinin başladığı Ming hükümeti Müslümanlara karşı çelişkili bir tavır takınmıştır. Hükümdarlar bir yandan İslam'ı olumlu değerlendirip sayg1 göstermekte; öte yandan Müslümanların özel örflerini ve kültürünü yok ederek onları Çin kültürüne asimile etmeye çalışmaktaydılar. Ancak genel olarak Ming hükümdarlarının çoğunun İslam'a karşı samimi bir tutum sergilemiş oldukları söylenebilir. Onların emriyle camiler inşa edilmiştir. Hatta bazı hükümdarların İslam'1 kabul ettiklerine dair rivayetler bile halk arasında dolaşmaktadır. ${ }^{16} \mathrm{Hükümdarların}$ yazdıkları şiirler, İslam'a uyguladıkları koruyucu ve teşvik edici politikalar, bu olumlu tavrın işaretleri olarak görülebilir. ${ }^{17}$

İslam'a ve Müslümanlara yönelik mezkur çelişkili tutum Ming hükümetinin yabancılar için koyduğu yasaklarda kolaylıkla görülebilir. ${ }^{18}$ Ming hükümdarlarının olumlu tavrı nedeniyle, bu yasakların arkasında yatan gerekçeler tartışmalı bir konu olmuştur. Bazıları İmparator Tai Zu’nun (ö. 800/1398, 明太祖) Müslümanları Çinlilerin düşmanlığından korumak amacıyla bu politikaları uyguladığı görüşünü ileri sürmüştür. ${ }^{19}$ Diğerleri ise, bu politikaların Müslümanları İslam'a imandan Çin'e sadakate dönüştürmek, özel kimliklerini yok etmek ve dolayısıyla Çin kültürüne asimile etmek amacıyla düzenlendiğini savunmaktadır. ${ }^{20}$ Nitekim, İmparator Tai Zu'yla doğrudan ilgili klasik eserde farklı azınlıklar için çeşitli yönetim makamlarının tesis edildiği anlatıldıktan sonra, onların bunun sayesinde medenileşmeleri ve Ming hükümdarlarına sadık olmalarının beklendiği açıklanmıştır. ${ }^{21}$

16 Bai, Çin İslamı `nın Küçük Tarihi, 66. İslam’ı kabul eden Ming hükümdarlarıyla ilgili araştırmalar hakkında bkz. Ming-Dao, Ma, Ming Kraliyet Ailesinin Inancının Illk Tahlili (明朝皇室信仰考 初稿) (Taipei: Zhongguo Huijiao Wenhua Jijinhui, 1984).

17 Ling-Gui Wang, Çin İslam Tarihi (中國伊斯蘭教史) (Beijing: Zhongguo Youyi Chuban Gongsi, 2014), 141-142. Tong-Xian Fu, Çin Íslam Tarihi (中國回教史) (Taipei: Taiwan Shangwu Yinshuguan, 1996), 95-97. Bai, Çin İslamı'nın Küçük Tarihi, 66.

18 Bu yasaklar hakkında bkz. Çin Felsefe Kitapları Elektronikleştirme Projesi, "Ming Hanedanlığının Kanun Kilavuz (6) (大明律集解附例卷之六),” erişim 20.03.2020. http://ctext.org/wiki. pl?if=gb\&chapter=466350. Bilinmeyen yazar, Ming Tai Zu Imparatorunun Gerçek Kaydl (1) ( 明太祖實錄卷一) (Taipei: Institute of History and Philology, Academia Sinica, 1968), 525.

19 Hajji Yusuf Chang, “The Hui (Muslim) Minority in China: An Historical Overview," in Islam in China: Key Papers (1), ed. Michael Dillon, (Folkstone: Global Oriental, 2009), 136. Ma, Ming Kraliyet Ailesinin Inancinın Illk Tahlili, 41-42.

20 Bai, Çin İslamı'nın Küçük Tarihi, 66. Zhen-Gui Yu, Çin Hanedanlıkları ve İslam (中國歷代政 權與伊斯蘭教) (Yinchuan: Ningxia Renmin Chubanshe, 1996), 115.

21 Bilinmeyen yazar, Ming Tai Zu Imparatorunun Gerçek Kaydı (4), 3307-3308. 
$\mathrm{Bu}$ tartışmaları bir kenara bıraktığımızda, Ming hükümetinin politikalarının Müslümanları önemli bir şekilde etkilediğini söylemek gerekir. Bu yüzden Müslümanlar, Ming hanedanlığı'nın ilk dönemlerinde maddi yönden Çin kültürünü kabul etmeye başlamıştır. Arap, Fars ve Türk adların yerini Çinli isimler almışlar, ana dilllerini terk ederek Çince konuşmaya başlamışlar, geleneksel Çin kıyafetini giyinmiş ve Çin kültürüne uygun yeni örfler geliştirmişlerdir. ${ }^{22}$ Bunun yanı sıra, Ming hükümetinin dış politikası dışa kapalı olduğu için Çin'deki Müslümanların dünya Müslüman ümmetiyle iletişimi azalmıştır. Bütün bunlar, Müslümanların dini bilincini olumsuz yönden etkilemiştir. Bunun bir sonucu olarak da Çin'deki İslam gün geçtikçe zayıflamaya başlamıştır. ${ }^{23}$

\section{İslam'ın Düşünsel Yerelleşmesi}

Ming hanedanlığının son döneminde ilk başlarda maddi yönle sınırlı kalan yerelleşme süreci, hızlı bir şekilde düşünsel yöne kaymıştır. Müslümanların anadillerini terk ederek Çince konuşmayı kabul etmeleri, ister istemez İslami asıl bilgilerini elde etmelerine bir engel oluşturmuştur, bu da onları doğru inançtan uzaklaşma riskiyle karşı karşıya bırakmıştır. ${ }^{24}$ Nitekim bu durum Çinli Müslüman âlimlerinin dikkatini çekmiştir. Çin İslamı'nın en önemli klasik eserlerinden olan İslam Dünyasının Ayinleri'ne yazılan son sözde, o dönemdeki İslam'ın çarpıtılmış olduğu, bu çarpıtılmış anlayışın Müslümanlar arasında dolaşımda olduğu ve dolayısıyla onların dinden uzaklaştığ ifade edilmiştir. ${ }^{25} \mathrm{Bu}$ nedenle, din konusunda Müslümanları doğru bir şekilde bilgilendirmek ve onların imanını güçlendirmek için, Kuran'1 Çinceye çevirme, Çince dini kitapları yazma, Konfüçyüsçü düşüncelerle

22 Wang, Çin İslam Tarih, 137-138, 183. Shou-Jiang Mi and Jia You, Çin İslamı'nın Kısa Tarihi (中國伊斯蘭教簡史) (Beijing: Zongjiao Wenhua Chubanshe, 2000), 120. Michael Dillon, China's Muslim Hui Community: Migration, Settlement and Sects (Richmond Surrey: Curzon Press, 1999), 30-31. Wu Maerjiang, "Klasik İslam Eserlerinin Çince'ye Tercüme Faaliyetlerinin Çin'de İslamiyet'in Gelişimine Katkısı," Edebali İslamiyat Dergisi 2/4 (Kasım 2018): 54.

23 Wang, Çin İslam Tarih, 142.

24 Chang-Kuan Lin, Çin Íslam'ının Gelişmeleri ve Hareketleri (中國回教之發展及其運動) (Taipei: Zhonghua Mingguo Alabo Wenhua Jingji Xiehui, 1996), 21, 34. Mi \& You, Çin İslamı'nın Kısa Tarihi, 151. Ayrıca Qing hanedanlığı döneminde yazılan eserlerde dil sıkıntısının Müslümanları dinden uzaklaştırdığı ve dini bilgileri edinmelerini engellediği görüşleri ortaya koyulmuştur. Bkz. dipnot 25..

25 Cheng-Long Ding “İslam Dünyasının Ayinlerinin Son Sözü (天方典禮跋),” Liu Zhi, Íslam Dünyasının Ayinleri (天方典禮), eds. Jia-Bin Zhang and Yong-Hao Du, (Tianjin: Tianjin Guji Chubanshe, 1988), 229. Aynı görüşü ortaya koyan diğer kayat ise Ke-Zong Shi, "İslam'la İlgili Kuşkuların Çözümlenmesi'nin Ön Sözü (清真釋疑序),” aktarılan Zhan-Ming Ma, İslam 'la Illgili Kuşkuların Çözümlenmesi Incelemesi (清真釋疑研究) (Beijing: Zhongguo Shehui Kexue Chubanshe, 2013), 64. 
İslami bilgileri açıklama ve Çin usulüne uygun olarak İslam eğitim sistemi kurma gibi çeşitli girişimler başlatılmıştır.

Bu girişimler Müslüman topluluklarla sınırlı kalmayıp geleneksel Konfüçyüsçü eğitim gören Çin bilginlerinin İslam'la ilgili yanlış anlamalarını düzeltmeyi de amaçlamıştır. Onlara göre, Çin kültür sisteminde son derece önemli olan Konfüçyüs, Müslümanlar için hiçbir anlam ifade etmemesi; bu da Müslümanların medeniyetsiz, atalarına saygı göstermedikleri, Çinlileri bağlayan Kofüçyüsçü sosyal, siyasi, dini normlardan bihaber oldukları anlamında yorumlanmıştır. ${ }^{26}$ Bu bağlamda yukarıda sözü geçen girişimler İslam’1 Konfüçyüsçü düşüncelerle bütünleştirme ve onu doğru anlatmayı amaçladığı için, Müslümanların Çin bilginlerinin önyargılarına karşı etkin bir savunma ve kendini ifade etme yolu olduğunu da söylemek mümkündür. Bunun sayesinde İslam, Budizm’in Çin tarihinde yaşadığ 1 sıkıntıdan kaçınabilmiştir. ${ }^{27}$

İslam'ın düşünsel yerelleşmesinin, amaçları itibarıyla, Müslüman toplulukları için bir tür ihya ve 1slah hareketi olarak düşünülmesi mümkündür. Bu nedenle yerelleşme sürecinin, İslami prensipleri yok ettiğini değil, tam tersine onları tekrar ortaya çıkardığını ve güçlendirdiğini söylemek gerekir. Aşağıda bunun nasıl gerçekleştirildiğini anlamak amacıyla, Çin İslam tarihinde yaşanan önemli yerelleşme hareketleri olarak görülenler üzerinde durulacaktır.

\section{Çin Medrese Eğitim Sisteminin (jingtang jiaoyu, 經堂教育) Kuruluşu}

Ming hanedanlığının orta döneminde, İslami bilgiler konusunda yaşanan eksiklik nedeniyle, Müslüman topluluklar içinde din eğitimi meselesi gündeme gelmiştir. Çin medrese eğitim sisteminin kurucusu Hu Deng-Zhou (ö. 1005/1597, 胡登洲), çocukluğunda hem geleneksel Konfüçyüsçü eğitim tamamlamış hem de ünlü bir âlim tarafından yetiştirilmiştir. ${ }^{28}$ Hacdan döndükten sonra Müslümanların doğru din bilgilerini yittirdiklerini gören $\mathrm{Hu}$, ilk başlarda İslami bilgilerini öğretmek amaciyla öğrencileri kendi evine davet etmiş ve kendi imkânlarıyla onları barındırmaya ve yedirmeye çalışmıştır. Hu'nun öğrencileri, ondan sonra medrese sistemi

26 Raphael Israeli, Islam in China: Religion, Ethnicity, Culture, and Politics (Oxford: Lexintong Books, 2002), 11.

27 Wen-Jong Yang, “Çin İslamı’nın Düşünceleri ve Geleneğinin Yerelleşmesi İncelemesi (論中國 伊斯蘭思想與傳統之在地化), ” in Localization of Islam in China (伊斯蘭在地化: 中國伊斯 蘭發展之探討), ed. Chang-Kuan Lin (Hong Kong: The Research Institute for the Humanities, The Chinese University of Hong Kong, 2015), 68.

28 Zong-Ping Sha, "Çin Mederese Eğitim Sisteminden Han Kitaplarına: Müslümanların Çinlileşmesine Giriş (從經堂教育到漢文著書: 穆斯林漢化初探), ” in Lin, Localization of Islam in China, 86. 
geliştirmişlerdir. Okul (medrese) cami içinde kurulmuştur. Öğrencilerin ihtiyaçları ise cami etrafındaki cemaat tarafından karşılanmaktaydı. Ming hanedanlığı'nın son dönemlerinde, bu eğitim sistemi Müslümanların yoğun bulundukları bölgelere yayılmış ve Shaanxi, Shandong, Yunnan ve Jiangnan olarak dört akım ortaya çıkmışt. ${ }^{29}$

İslami bilgileri doğru bir şekilde aktarmayı, âlimler ve din adamları yetiştirmeyi hedefleyen Çin medrese eğitim sistemi üç seviyeden oluşmaktadır. İlk seviyede çocuklara temel İslami bilgiler, Kur'an'ın kısa ve kolay ayetleri öğretilmektedir. İkinci seviye din konusunda sistematik bir din eğitimi göremeyen yetişkinler için tesis edilmiştir. Bu seviyede Kuran' dan seçilen ayetler okutulmaktadır. En yüksek seviye ise, camilerde hizmet veren din adamları yetiştirmeyi amaçlamaktadır. Öğrencilerin bu üç seviyeyi sırayla ve ara vermeksizin tamamlamaları şart değildir. İsteğe bağlı derse girebilirler. Seviyelerin tamamlanmasıyla alakalı herhangi bir süre sinırlaması da yoktur. ${ }^{30}$

Çin medrese eğitim sisteminin gelişmesiyle birlikte klasik 13 ders kitabı (14 olduğunu söyleyen de vardır) ortaya çıkmıştır. Bu kitaplar alet ilimleri ve temel bilgileri içerecek şekilde hazırlanmıştır. Alet ilimleri Arapça ve Farsça dilbilgisi, belagat ve mantık ilmini kapsamaktadır. Temel bilgi konuları ise tevhit, tefsir, hadis, kelam, fikıh ve tasavvuf olarak sınıflandırılabilir. Yukarıda sözü geçen akımlar, önem verdikleri alanlar farklı olduğu için, kendi uzmanlık alanlarıyla Çinli Müslümanlar arasında tanınmaktadır. Hu Deng-Zhou ve öğrencilerinin temsil ettiği Shaanxi akımı, incelik ve niteliğe önem vererek Arapça klasik eserleri ve tevhit alanında uzmanlaşmıştır. Shandong akımı enginlik ve tecrübeyi ön plana çıkartarak Farsça dilbilgisi ve fikıh alanında meşhur olmuştur. ${ }^{31}$

Burada dikkat edilmesi gereken bir husus, Çin medreselerinde ders işlerken kullanılan dildir. Derslerde kullanılan kitaplar İslam dünyasından getirilmiştir. Ancak, Ming hanedanlığı döneminde Müslümanlar İslami bilgilerin en önemli taşıyıcısı olan Arapça ve Farsçayı bilmez bir hale gelmişlerdir. Bu bağlamda Arapça ve Farsça yazılan dini kitapları Çinceye çevirme ve anlamlarını açıklama ihtiyacı hasıl olmuş ve bunu karşılamak amacıyla Çinli âlimler özel bir tercüme yöntemi geliştirmişlerdir. Medrese dili (jingtangyu, 經堂語) diye adlandırılan bu yöntemde, Çince, Arapça ve Farsça dini terimleri ifade etmek için kullanılmıştır. Âlimler, bunu yapmak için ya Konfüçyüsçülük, Budizm ve Daoizm’e ait özel

29 Qiang Ma "Field Investigation and Thing on the Hui and Islamic Cultural Education (回族伊 斯蘭文化教育的田野調查及思考),” Researches on the Hui (回族研究) 52/4 (2003): 104.

30 Sha, "Çin Mederese Eğitim Sisteminden Han Kitaplarına," 92.

31 Yang and Ma, İslam Uzun Vadeli Muhteşemdir, 208. 
terimleri ödünç almışlar veya transliterasyon yapmışlardır. Ancak böylece hocaların dersi anlatması ve dini terimlerin doğru bir şekilde anlaşılması mümkün olmuştur. ${ }^{32}$

Çin medrese eğitim sistemi ve medrese dilinin ortaya çıkışı, İslam'ın yerelleşmesinin bir ifadesidir. Hatta Çinli akademisyenlere göre bu ikisi günümüzdeki Huileri millileştiren unsurlardan biridir. ${ }^{33} \mathrm{Bu}$ kısımdan anlaşıldığ 1 üzere, hem medrese sistemi hem de geliştirilmiş olan tercüme yöntemi, dini bilgilerin muhafaza edilmesi ve nesilden nesle aktarılması amacıyla tesis edilmişlerdir. Bu bakımdan her ikisinin de İslam'ın Çin'de yayılmasının en önemli faktörlerinden biri olduğunu söylemek gerekir. ${ }^{34}$ Ancak zamanla Çin medrese eğitim sisteminin gelişmesiyle birlikte, mevcut ders kitapları öğrencilerin ihtiyaçlarını karşılayamaz bir hale gelmiştir. ${ }^{35}$

32 Çin Medrese Eğitiminde kullanılan "jingtangyu," âlimlerin ders işlerken yarattıkları tercüme yönetimi olarak düşünülebilir. Onlar Arapça, Türkçe ve Farsça terimler Çin harfleriyle transliterasyon yapmakta (vice versa) veya Çince sözcüklerden anlamları yakın olanları ödünç alarak yabancı terimler ifade etmektedirler. Bu yüzden jingtangyu'nün Çince, Arapça, Türkçe ve Farsça sözcükler bir araya getiren, fakat Çince dilbilgisi kurallarına uygun karma bir dil olduğunu söylemek gerekmektedir. Aynı zamanda Xiaojing (消經、小經) olarak da bilinen Xiaoerjin (小兒 錦) veya Xiaoerjing (小兒經), Çin medrese eğitiminin kuruluşuyla birlikte ortaya çıkan özel bir yöntemdir. Genel olarak Çinli akademisyenler xiaoerjin'den jingtangyu'dan bağımsız bir şekilde söz etmektedirler. Bu yüzden ikisi de Çin medrese eğitim sisteminden kaynaklanmasına rağmen, Xiaoerjin'in jintangyu'yla paralel olarak diğer bir yöntem olduğunu söylemek gerekmektedir. İşlev itibarıyla, Xiaoerjin Arap alfabesiyle Çince transliterasyon yapan bir yöntemdir. Örneğin

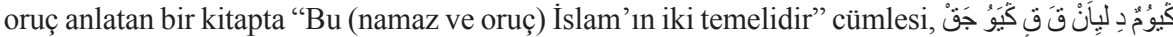
ش (這個是伊斯倆木教門的兩個跟腳) şeklinde yazılmıştır. Bu örnekten görüldüğü üzere, bu cümle Arap alfabesiyle yazılmasına rağmen, Çince telaffuzunu ifade etmektedir.. Jingtangyu'nün diğer özel bir ifadesi, Çinli Müslümanların kullandıkları özel terimlerde görülmektedir. Talebe ( 塔里布. talibu), kalem (干蘭, ganlan), abdest (阿布代斯, abudaisi) ve Reis (萊衣斯, laiyisi) gibi yabancı dilden doğrudan transliterasyonu yapılan terimler buna örnek olarak verilmek mümkündür. Ayrica kurban etme (下刀), vefat etme (歸真), bereket(回賜) ve setr-i avret (羛體) gibi terimler ise Çinceden türeyerek özel İslami kavramlarla ifade edilmiştir. Jingtangyu ve xiaoerjin ile ilgili bilgiler bkz. Yang \& Ma, İslam Uzun Vadeli Muhteşemdir, 208. Mi \& You, Çin İslamı'nın Kısa Tarihi, 153-154. Sha, "Çin Mederese Eğitim Sisteminden Han Kitaplarına," 92. Dillon, China's Muslim Hui Community, 154-155. Shu-Sen Qiu ed., Çin'deki Hui Etnik Grubu Tarihi (中國回 族史) (Ningxia: Xingxia Renmin Chubanshe, 1996), 382-384, 520-521. A Yibulaheimai, "Hui Etnik Grubundaki “Xiaojing”in Karakter Sistemi Incelemesi (回族”消經”文字體系研究),” Etnik Diller (民族語文) 1(1992): 25-32. Ma \& Ding, Çin İslamı'nın Kültür Kategorisi ve Etnik Özellikleri, 145. Sha, "Çin Mederese Eğitim Sisteminden Han Kitaplarına," 92

33 Mi and You, Çin İslamı'nın Kısa Tarihi, 155. Guo-Xi Tie, “Çin İslamı Eğitimine Giriş (淺論 中國伊斯蘭教教育)”, Researches on the Hui (回族研究) 45/1 (2002):72.

34 Ünal, "Çin Tarzı İslam."

35 Chang-Kuan Lin, ders kitaplarının tefsir, felsefe, dilbilgisi ve belagatla sınırılı kalması ve büyük kısmının tasavvufa dayanmasının Çin medrese eğitiminin eksikliği olduğuna işaret etmiştir. Ona göre bu eksikliği gidermek için Çince dini kitapları yazma eğilimi baş göstermiştir. Ayrıca Ling-Gui Wang da Arapça ve Farsça'dan çevrilen ders kitaplarının talebelerin ihtiyaçlarını karşılamaz bir hale geldiğini ve dolayısıyla Konfüçyüsçü düşüncelerle İslami bilgileri açılama faaliyetinin başlatıldığını ifade etmiştir. Bkz. Lin, Çin İslam'ının Gelişmeleri ve Hareketleri, 37-38. Wang, Çin İslam Tarih, 207. 
Bu durum, İslam'ın yerelleşmesini bir adım daha ileri götürmüş ve Konfüçyüsçü düşüncelerle İslam'ı açıklama ve Çince dini kitapları yazma sürecinin başlamasına yol açmıştır.

\section{İslam'ın Konfüçü̈sçü Düşüncelerle Diyalogu}

İslam'ın Konfuçyüsçü düşüncelerle diyalogu ve bütünleşmesi, esas olarak Çince dini kitaplarının ortaya çıkışıyla başlamıştır. Söz konusu dini kitaplar, Kur'an başta olmak üzere, Arapça ve Farsça klasik dini eserlerden Çinceye çevrilmiştir. Bu girişimde çaba sarfeden âlimler iyi bir Müslüman olarak yetiştirildikleri ve kaliteli geleneksel Konfüçyüsçü eğitim gördükleri için hem İslam hem de Konfüçyüsçü alanda uzmanlaşmış kişilerdir. Bunlar, herkesin anlamasını kolaylaştırmak amacıyla İslami düşünceleri Konfüçyüsçü kavramlar ve ifadelerle açılamaya çalışmışlardır. Bunun da, dini kitapları tercümenin (hanwen yizhu, 漢文譯著), veya Konfüçyüsçü düşüncelerle Kur'an'1 ve İslam'1 açıklama (yiru shijing, 以 儒釋經) olarak adlandırılan girişimi başlattığını söylemek doğru bir tespit olur. ${ }^{36}$

Bu girişimler aşamalı bir şekilde gelişmiştir. Genel olarak Çinli akademisyenler bu gelişmeyi üç döneme ayırmışlardır. İlk dönem Ming hanedanlığının son dönemleri ve Qing hanedanlığının ilk dönemlerine denk gelmektedir. Yukarıda değinilen Çinli bilginlerin önyargıları nedeniyle, âlimler ilk dönemde savunmacı bir tavır sergileyerek belli bir dereceye kadar Çin kültürüne karşı mesafeli durmaktaydılar. Eserlerinde İslami prensiplerle çeliştiğini düşündükleri düşünceleri eleştirmişler; İslam'ın evrensel dünya görüşü ve hayata bakışını savunmuşlar ve dolayısıyla Çin İslamı'nın düşünce sistemi için bir temel görevi görmüşlerdir. ${ }^{37}$ Wang Dai-Yu (ö. $1070 ? / 1660$ ? $)^{38}$ bu dönemin önemli bir temsilcisi olarak kabul edilebilir.

36 Çin akademik camiasında Arapça ve Farsçadan Çinceye çevrilen klasik dini eserlerin oluşturduğu külliyat “Han kitap (漢刻它布)” terimiyle kastedilmektedir. İlgili bilgiler hakkında bkz. Ünal, "Çin Tarzi İslam." Zvi Ben-Dor Benite, The Dao of Muhammad: A Cultural History of Muslims in Late Imperial China (Cambridge \& London: The Havard University Asia Center, 2005), 5. Esra Çifçi, "Han Kitap," TDV İslam Ansiklopedisi, https://islamansiklopedisi.org.tr/han-kitap, erişim 15.06.2020.

37 Yang \& Ma, İslam Uzun Vadeli Muhteşemdir, 177.

38 Wang Dai-Yu'nün hayatıyla ilgili bilgiler kendi anlatımıyla sınırlıdır. Wang'ın atalarının Kâbe'den Çin'e geldikleri, Konfüçyüsçülük ve onun İslam'da uzmanlaşmış büyük Çinli âlimlerden eğitim gördüğü, öğrenciler yetiştirdiği ve eserler kaleme almış olduğuna dair bilgiler, onun hakkında genel olarak kabul edilen bilgilerdir. Íslam 'ın Doğru Açıklanması (Zhengjiao Zhenquan, 正教真 詮), Íslam 'ın Büyük İlmi (Qingzhen Daxue, 清真大學) ve öğrencileri tarafından derlenen Nadir ve Doğru Cevaplar (Xizhen Zhengda, 希真正答) en önemli eserleri arasında yer almaktadır. Bkz. Yi-Jiu Jin, Wang Dai-Yu’nün Düşüncelerinin İncelenmesi (王岱輿思想研究) (Beijing: Minzu Chubanshe, 2008), 62-97. Benite, The Dao of Muhammad, 134-137. Wu Maerjiang, "Klasik İslam Eserlerinin Çince’ye Tercüme Faaliyetlerinin Çin'de İslamiyet'in Gelişimine Katkısı,” 62-65. 
Ma Zhu (ö. 1122/1711) ${ }^{39}$ ve Liu Zhi (ö. 1177/1764) ${ }^{40}$ ikinci dönem temsil etmektedir. Bu dönemde tercüme ve İslam'ın Konfüçyüsçü açıklaması doruğa çıkmıştır. Bu zamanlarda kaleme alınmış olan Çince dini kitapları, önceki dönemden farklı olarak sırf İslam düşüncelerini savunmakla kalmamış, Konfüçyüsçü düşüncelere de önem vermiştir. Ayrıca, bu eserlerde yalnızca Budist düşünceler eleştirilmiş, Konfüçyüsçülük ve Daoizm üzerine bu tür eleştirilerden ise kaçınılmıştır. ${ }^{41}$ Bunun nedenlerinden birisi, Ma Zhu ve Liu Zhi gibi âlimlerin İslam'1 Daoist ve geleneksel Konfüçyüsçü düşünceleri birleştiren Yeni Konfüçyanizm'le

39 Ma Zhu, Yuan döneminde Yunnan eyaletini yöneten ünlü bir Müslüman vali, Ajall Shams al-Din Omar (Saidianchi Shansiding Wuma'er, 賽典赤瞻思丁烏馬兒)' 1 n torunlarındandir. Atalar1 ve Wang Dai-Yu'ye hayranlığı nedeniyle Ma, Shandong, Jiangnan'daki Müslüman merkezleri ve Beijing Niujie Camii (Ox Street Mosque)'ini ziyaret etmiş, kendisini dini kitapları yazmaya adamıştır. Ma Zhu'nun en önemli eserlerinden biri olan İslam 'ın Kılavuzu (Qingzhen Zhinan, 清 真指南) 10 ciltten oluşmaktadır. Bu eser İslam ve Huilerin tarihi, tefsir, felsefe, fikıh, astronomi ve mit gibi çeşitli bilgiler içerip Çin İslamı hakkında oldukça kapsamlı bir kaynaktır. Ayrıca, Ma Zhu, bu eserle Yeni Konfüçyanist düşünceleriyle Allah'ın varlı̆̆ı, dünyanın tanınması ve kişiler arasında olması gereken ilişkileri ele almıştır. Bu bakımdan Íslam 'ın Kılavuzu'nun, İslam ontolojisi, epistemolojisi ve ahlakı gibi önemli bilgiler kapsayan değerli bir eser olduğunu söylemek mümkündür. Bkz. Benite, The Dao of Muhammad, 137-139. Huai-Zhong Yang and Zhen-Gui Yu, Islam ile Çin Kültürü (伊斯蘭與中國文化) (Ningxia: Ningxia Renmin Chubanshe, 1996), 405-412. Wu Maerjiang, “Klasik İslam Eserlerinin Çince'ye Tercüme Faaliyetlerinin Çin'de İslamiyet'in Gelişimine Katkısı," 68-70.

40 Çinli âlim geleneğine mensup bir ailede doğan Liu Zhi, küçük yaşlarda Çin medrese eğitimi ve geleneksel Konfüçyüsçü eğitim görmüştür. Liu, Ma Zhu gibi, eğitimini tamamladıktan sonra daha fazla bilgi elde etmek için seyahate çıkmıştır. Seyahat sırasında ünlü Çinli âlimlerle tanışmış ve Farsça yazılan Peygamber Muhammed'in biyografisini elde etmiştir. Bu eser onun önemli eserlerinden birisinin temelini oluşturmuştur. Liu Zhi'nın düşünceleri geleneksel Çin felsefesi (Konfüçyüsçülük, Yeni Konfüçyanizm, Daoizm ve Budizm) ve İslam, özellikle de tasavvuf temelinde kurulmuştur. Liu hayat boyunca yüzlerce kitap kaleme almıştır. Bunlardan ancak 50-60 kadarı yayımlanmıştır. Geri kalanları kaybolmuştur. Onun en önemli eserlerinden biri, İslam kozmolojisini anlatan İslam 'ın Metafiziği (Tianfang Xingli, 天方性理)'dir. Bu kitap insan ile dünyanın karşılıklı ilişkisini mistik bir şekilde anlattığı için tasavvufi özellikler taşımaktadır. Diğer eser İslam 'in Ayinleri (Tianfang Dianli, 天方典禮)dir ve Liu Zhi'nın tefsir, hadis ve fıkıh gibi alanlarda seçtiği önemli metinlerin çevirilerini içermektedir. O, bu eserde İslam'ın dini emirleri ile Konfüçyüsçü toplumsal normları telif etmeye çalışmıştır. Son olarak Orta Doğu'daki Peygamber Kayttları (Tianfang Zhisheng Lu, 天方至聖錄), kronolojik bir şekilde Peygamber Muhammed'in hayatını kaydetmektedir. Bkz. James D. Frankel, Rectifying God's Name: Liu Zhi's Cofucian Translation of Monotheism and Islamic Law (Hawai'i: University of Hawai'i Press, 2011), 5-10. Yi-Jiu Jin, Çin İslamı'nın Gizeminin Keşfi: Liu Zhi Incelemesi ( 中國伊斯蘭探秘: 劉智研究) (Beijing: Zhongguo Renmin Daxue Chubanshe, 2010). Yang \& Yu, İslam ile Çin Kültürü, 400-401. Wu Maerjiang, "Klasik İslam Eserlerinin Çince’ye Tercüme Faaliyetlerinin Çin'de İslamiyet'in Gelişimine Katkısı," 65-68.

41 Mi \& You, Çin İslamı 'nın Kısa Tarihi, 165. Lin, Çin İslam'ının Gelişmeleri ve Hareketleri, 66-68. Yang \& Ma, İslam Uzun Vadeli Muhteşemdir, 185-187. Bai, Çin İslamı'nın Küçük Tarihi, 76. 
(Neo-Confucianism) açıklamalarıdır. ${ }^{42}$ Dolayısıyla bu dönemdeki eserler en çok Konfüçyüsçü-Müslümanlık (Hui-Ru, 回儒) niteliğini taşımıştır. ${ }^{43}$ Bunun içindir ki Bai Shou-Yi, İslam'ı açıklamada Ma Zhu'nun Konfüçyüsçülüğe ağırlık verdiği ve Liu Zhi'nın tamamen ona dayandığını ifade etmiştir. ${ }^{44}$ Nitekim o dönemdeki önemli Çinli bilginler, Liu'nun düşüncelerinin ve konumunun, Çince dini kitapları arasında en çok "Çinli" (Konfüçyüsçü) olduğunu kabul etmişlerdir. ${ }^{45}$

Qing hanedanlığının orta ve son döneminde, toplumda kargaşa yaşanmaya başlamıştır. Hükümetin Müslümanlara uyguladığı politiklar da sertleşmiş hatta zülüm halini almıştır. ${ }^{46}$ Bunun bir sonucu olarak da dini kitapları tercüme ve Konfüçyüsçü düşüncelerle İslam'ı açıklama bir süre kesilmiş, ancak Ma De-Xin (ö. 1290/1874) $)^{47}$ hacdan geldikten sonra yeniden başlamıştır. Önceki iki döneme nazaran bu dönemdeki eserlerde farklı bir eğilim göstermektedir. Konfüçyüsçü düşünceler ve İslam arasındaki farklılık ön plana çıkmıştır. Ma De-Xin'e göre İslam Allah inancını merkeze almasıyla, kişilerarası ilişkiler, toplumsal ahlak sistemi, bireyin aile, toplum ve millet ile ilgili sorumlulukları temelinde kurulan Konfüçyüsçülükten farklılaşır. Bunun üzerine önceki büyük âlimlerin düşüncelerini eleştirici bir tavırla toparlamaya çalışmış ve yanlışı doğrudan ayırt ederek kendi kuramlarını

42 Ünal, "Çin Tarzı İslam."

43 Konfüçyanist Müslümanlık” (Hui-Ru, 回儒), klasik Çin Konfüçyanist kültürü ile İslam medeniyeti ve kültürünün bir araya gelmesiyle oluşan bir kültür sentezidir. Ayrıntılar için bkz. Ünal, "Çin Tarzi İslam."

44 Bai, Çin İslamı'nın Küçük Tarihi, 76.

45 Frankel, Rectifying God's Name, 30.

46 Lin, Çin İslam'ının Gelişmeleri ve Hareketleri, 106-109. Bai, Çin İslamı'nın Küçük Tarihi, 77-85. Wang, Çin Islam Tarih, 189-192. Chang, "The Hui (Muslim) Minority in China: An Historical Overview," 137-138. Israeli, Islam in China, 286. Yang \& Ma, Islam Uzun Vadeli Muhteşemdir, 53-56.

47 Ma De-Xin, küçük yaştan itibaren İslam eğitimi görmüştür. Ma, 40 yaşındayken geleneksel Çin kültürü ve Konfüçyüsçülügü öğrenmeye başlamış ve 50 yaşındayken "doğru inanca ulaşmadığg ve ünlü âlimlerle nadiren karşılaştığı” için hacca çıkmıştır. Hac sırasında Hindistan, Bangladeş, Kahire, Kudüs ve İstanbul gibi Güney Asya ve Orta Doğu'daki şehirlerde sekiz sene kalmış ve yerli âlimlerle iletişim kurmuştur. Çin'e geldikten sonra Yunnan'da medrese ve dolayısıyla Çin medrese eğitiminin Yunnan ekolünü kurmuştur. Ma, Çince ve Arapça iki dilde kitap yazmaktaydı. Eserlerinin sayısı oldukça fazladır. Onlardan bazıları Dört Klasik Eserlerin Esası Toplaması (Sidian Yaohui, 四典要會) ve Dünyanın Yaratılışının Aslına Dönmesi (Dahua Zonggui, 大化 總歸)' dir. Genel olarak bu eserler fikıh, felsefe, kozmoloji, Arapça dilbilgisi, tefsir ve akait gibi çeşitli alanları kapsamaktadır. Ma De-Xin, Ma Zhu'dan sonra en üretken âlim olarak tanınmıştır. Onun eserleri sayesinde Çin İslam düşüncesi yeni bir boyuta ulaşmıştır. Bkz. Yang \& Ma, İslam Uzun Vadeli Muhteşemdir, 185-187. Yang \& Yu, İslam ile Çin Kültürü, 412-417. Bai, Çin İslamı'nın Küçük Tarihi, 86. Wu Maerjiang, "Klasik İslam Eserlerinin Çince’ye Tercüme Faaliyetlerinin Çin'de İslamiyet'in Gelişimine Katkısı,” 70-73. Ünal, "Çin Tarzı İslam.” 
geliştirmiş̧tir. ${ }^{48}$ Böylelikle Ma, önceki büyük âlimlere nazaran kuramlarına daha çok Tasavvuf düşünceleri katmıştır. ${ }^{49}$ Netice itibarıyla Allah'ın Hâlık ismi (zhenyilun, 真一論), O’nun dünyayı yaratışı (dahualun, 大化論), ahiret ve diriliş (youming yu fushenshuo, 幽冥與復生說) gibi çeşitli hususlarda daha derin bir bakışa ulaşmış ve bunlarla Konfüçyüsçülüğün ontoloji, kozmoloji ve ölüm gibi konulardaki eksikliğini tamamlamayı amaçlamıştı..$^{50}$

Yukarıdan anlaşıldığı üzere, Çin medrese eğitim sisteminin kuruluşu ve Çince dini kitapları yazımı, İslam'ın Çin toplumu ve geleneğiyle kaynaşmasını amaçlamaktadır. $\mathrm{Bu}$ iki yerelleşme girişimi sayesinde İslam Çin kültürüyle irtibat kurabilmiş ve dolayısıyla kendisine tamamen yabancı bir ortamda varlığını koruyabilmiştir. Öte yandan, Ma De-Xin'in düşüncelerinde görüldüğü gibi, yerelleşme sınırsız bir süreç değildir. Bu da İslam'ın Çin kültürüne asimile olmadığının en önemli göstergelerinden birisidir. Bu konuda en önemli olay Çinli Müslümanların global Müslüman ümmetiyle yeniden temas kurmaları ve bunun bir sonucu olarak da ortaya çıkan reformist gruplar ve düşüncelerdir.

\section{İslami İhya ve Islah Hareketlerinin Orta Çıkışı}

Yerelleşmenin bir sonucu olarak İslam Çin'e ilk geldiği andan Qing hanedanlığına kadar geçen süreçte önemli değişime uğramıştır. Çinli Müslümanlar hem fiziksel hem kültürel hem de düşünsel açıdan önemli bir ölçüde yerelleşmiştir. Bu yerelleşme/ yerelleşme durumunun önemli sonuçlarından biri de burada bahsedilmeye değer bir diğer husus, Çin tarikatlarının ortaya çıkmasıdır ${ }^{51}$.

Tasavvuf yaklaşık 13. ve 14. yüzyılda Çin'e gelmesine rağmen, ancak 17. yüzyılın ortasınd etkisini göstermeye başlamıştır. Bu dönemden itibaren Tasavvufun gelişmesi

48 Yang \& Ma, İslam Uzun Vadeli Muhteşemdir, 187. Wang, Çin İslam Tarih, 215.

49 Wang, Çin İslam Tarih, 215.. Gui-Ping Yang, “Ma De-Xin's Da Hua Thoughts (馬德新的大化 思想),” Researches on the Hui (回族研究) 51/3 (2003):67.

50 Yang, "Ma De-Xin's Da Hua Thoughts," 66-70.

51 Çin'deki yerlileşmiş tarikatlara "menhuan” denilmektedir. Bu sözcüğün kaynağı hakkında bkz. Tong Ma, Çin İslamı'ndaki Mezhepler ve Tarikatların Menşeine Dair Bir İnceleme (中國伊斯 蘭教派門宦溯源) (Yinchuan: Ningxia Renmin Chubanshe, 1995), 35-36. 
ve etkisiyle çeşitli tarikatlar kurulmuştur. ${ }^{52}$ Bunların çoğu Çin'in kuzeybatısında yoğun olarak bulunmakta ve yerli ataerkil sistemle bütünleşmektedir. Her tarikatın hocas1/şeyhi, dini olduğu kadar siyasi ve iktisadi alanda da liderlik yapmakta ve dolayısıyla bir takım imtiyazlara sahip olmaktadır. Bu nedenle tarikatlar, dini kurallarla yönetilen sıkı bir hiyerarşi sistemine sahiptir. Bu özellikleriyle de tarikatlar, siyasi otoritelere bir tehdit oluşturmaktadır. Bir diğer ifadeyle, bu tarikatlar hem dini grupların hem feodal Çin sisteminin özelliklerini taşımaktadır. ${ }^{53}$ Nitekim Qing hanedanlığı'nın son zamanlarında tarikatlar arasındaki çatışmalar, Müslümanların bölgelerarası isyanlarına yol açmıştır.

Çin'deki yerelleşmiş tarikatlar, İslam dünyasındakilerden oldukça farklı özelliklere sahiptir. Bunların en önemlisi Çin tarikatlarının çok daha sekülerleşmiş olmasıdır. Müritler, manevi hayatlarında olduğu kadar ekonomik hayatlarında da mürşitlerine

52 10. ve 11. yüzy1llarda Tasavvuf Orta Asya' daki Türklerin büyük bir kısmı tarafından benimsenmiştir. 12. yüzyılın ikinci yarısı ve 14. yüzyılda sırayla Kübreviye ve Nakşibendî kurulduktan sonra, mensupları Çin'in kuzeybatı sınırlarında bulunmaya başlamıştır. Tasavvuf ve düşüncelerinin Çin'e girmesi muhtemelen bu dönemlerde meydana gelmiştir. Bununla birlikte tasavvufçuların Çin'deki faaliyetlerini doğrudan kaydeden kaynaklar eksik olduğu için, araştırmacılar ancak dolaylı olarak tarih kitapları, resmi dokümanlar ve kitabeler gibi kaynaklardan konuyla ilgili bilgileri edinebilmektedir. Örneğin Yuan Hükümetinin Fermanı'da (元典章) yer alan kayıtlara göre bazı Müslümanların sadece ibadet ettikleri ve üretim faaliyetini hiç yapmadıkları bilgisinden hareketle Yuan Hanedanlığı döneminde tasavvufçuların büyük miktarda Çin'e geldikleri sonucuna ulaşılmıştır. Bir diğer örnek olarak, Wang Jing-Zhai, Liu Zhi, Ma Zhu ve Ma De-Xin gibi büyük Çinli Müslüman âlimlerin eserlerinde de tasavvuf düşüncelere yer verilmiş veya ünlü şeyhlerden söz edilmiştir. Ayrıca Çin medrese eğitiminde kullanılan 13 ders kitabı da tasavvufi düşünceleri içermektedir. Onlardan bazıları büyük şeyhler tarafından kaleme alınmıştır. Hatta Çin medrese eğitim sisteminin kurucusu Hu Deng-Zhou'nun tasavvuf eğitimini aldığıyla ilgili görüşler ortaya atılmıştır. Doğrudan Tasavvuf ve tarikatlarla ilgili kayıtlar ancak Qing hanedanlığın ilk ve orta döneminde Tasavvuf etkisini gösterdikten ve Çin tarikatları kuruduktan sonra kolaylıkla görülmeye başlamıştır. Ayrıntılı bilgiler hakkında bkz. Lin, Çin İslam'ının Gelişmeleri ve Hareketleri, 77 78. Yi-Jiu Jin, Sufism in China (蘇菲主義在中國) (Beijing: Social Sciences Academic Press, 2013), 20-122. Si-Yuan Hu, Kadiriyah: The Spreading and Variation of A Western Sufi Order in China (嘎迪林耶: 一個西域蘇菲教團的在華傳播與變異), yayımlanmamıs yüksek lisans tezi, (Guangzhou: Jinan University, 2016), 10-16. Bao-Yu Ha, "Medrese Eğitiminin Mevcut Durumu ve Sorunlar1 Mütalaası I (經堂教育現狀及存在問題的調查研究(上)), ”Studies in World Religions(世界宗教研究), 6(2018): 186. Jun-Rong Wang, “Tasavvuf Düşünceleri ve Çin Felsefesi: Tasavvuf Eserlerinin Çin'deki Çevirileri ve Anlamlarının Tartışması (蘇菲思想與中 國哲學: 談蘇菲著作在中國的翻譯和意義), "Researches on the Hui (回族研究) 87/3(2012): 19-20. Yu-Jun Gu, Ming ve Qing Hanedanlığı Dönemlerinde Hui Etnik Grubunun Ĕgitimi ve Düşünceleri Araştırmaları (明清時期回族教育思想研究), yayımlanmamış doktora tezi, (Beijing: Minzu University of China, 2012), 92-99. Ünal, “Çin Tarzı İslam.” Çifçi, “Çin'de İlk İslami Entelektüel Çaba ve Konfüçyanist Müslümanlar (Hui-Ru),” 871-872.

53 Mi \& You, Çin İslamı'nın Kısa Tarihi, 150. 
bağlanmaktadırlar. ${ }^{54} \mathrm{Bu}$ yüzden mürşitlerin müritlerinin dini olduğu kadar seküler hayatları üzerinde de yetkileri oldukça güçlüdür. Öte yandan züht, türbe kültü, zikir ve mistik tecrübe peşinden koşma gibi hususlarda, Çin'deki ve İslam dünyasındaki tarikatlar bir dereceye kadar aynılık göstermektedir. Ancak bu hususlar, İslam'ın yakın tarihinde 1slah hareketlerinin yok etmeye çalıştı̆̆ 1 "bid'atlar" olduğu için, Çin İslamı'nda da düzeltilmesi gereken bir hata olarak algılanmaktadır..

İhya ve sslah hareketlerinin İslam dünyasında ortaya çıkışı, Çin tarikatlarının gelişim gösterdiği Qing hanedanlığı'nın son dönemine denk gelmektedir. Bu dönemde hacdan dönen Çinli Müslümanlar arasında Ma De-Xin gibi Konfüçyüsçü düşünceler ve İslam ilişkisi üzerinde yeniden düşünenler kadar, Vehhâbî ve Selefî düşünceler tarafından etkilenip İslam'ı 1slah etme ve arındırmayı savunanlar da mevcuttur. ${ }^{55} \mathrm{Bu}$ nedenle Çin İslamı, her yönden yerelleşmesi bağlamında bir ıslah sürecine girmiştir. Bu anlamda İslam'ın küreselleşmesi, uzun zamandır İslam dünyasından ayrılan Çin İslamı için bir esin kaynağı olmuştur. Islah düşünceleri artık Çin İslamı sahnesine çıkmıştır. Çin imparatorluğu döneminden Cumhuriyet dönemine girildiğinde, Müslümanlar yeni nizamda yeni ümitlerle yurt çapında ihya ve islah hareketlerini başlatmışlardır.

\section{Yihewani'nin Kuruluşu ve Ana Düşünceleri}

Çinli Müslümanların yoğun bulundukları Gansu eyaletinde ortaya çıkan Yihewani (伊赫瓦尼), Çin İslamı yakın tarihindeki en önemli akımlardan biridir. Çincede "Yihewani" sözcügü kardeş anlamına gelmekte olup, aynı anlamdaki Arapça

54 Yang \& Ma, İslam Uzun Vadeli Muhteşemdir, 146.

55 Bu çalışmanın üçüncü kısmında ele alınan Selefi düşünceleri taşıyan iki hareket, Yihewani ve Sailaifengye başta olmak üzere, yaklaşık aynı dönem veya daha geç bir dönemde, hacdan gelen ve İslam dünyasında okuyan Çinli Müslüman öğrenciler de kendilerini ihya ve ıslah hareketlerine adamışlardır. Çin'in kuzeybatısında ortaya çıkan Yihewani ve Sailaifengye'ye karşılıklı olarak söz konusu Müslümanların başlattıkları hareketler Çin'in doğusunda yoğunlaşmıştır. Onlar dini dergiler yayımlama, geleneksel dini bilgiler ve modern bilimsel bilgiler öğreten yeni usullü okullar kurma gibi yöntemlerle Çinli Müslümanlara doğru bir dini bilgiler aktarmaya ve etkin bir dini kimlik kazandırmaya çalışmışlardır. Dolayısıyla bu hareketlerin yöntem itibarıyla Yihewani ve Sailaifengye'den farklılaştığını söylemek mümkündür. Wang Hao-Ran, Ma Song-Ting, Da Pusheng Ha De-Cheng ve Wang Jing-Zhai, bu hareketlere önderlik eden ünlü Çinli âlimlere örnek olarak verilebilir. Bu hareketler hakkında bkz. Xiu-Ping Bao, "Çin İslam Derneğinin Kuruluşu ve Gelişmeleri (中國回教協會的創建及其發展), ” Xi-Lin Zhao ve Zhong-Fu Zhang eds., Allah'ın Emirlerinin Nesilden Nesle Geçişi ve Devamlılığı: İslam'ın Tayvan'daki Yayılması ve Öngörmeleri (主命的傳承與延續: 回教在台灣的發揚和展望) (Taipei: Chengchi University Press, 2019), 60-62. Chang-Kuan Lin, “Çin Cumhuriyeti’ndeki İslam: Çağdaş Çince Konuşan Müslüman Topluluğun Gelişmeleri İncelemesi (中華民國伊斯蘭: 當代漢語穆斯林社群發展 之解析),"Cross-Cultural Studies (文化越界) 11(Mart, 2014): 116-125. 
ihvân (اخوان) kelimesinin transliterasyonudur. Bu akım kutsal kaynaklara önem verdiği için, kutsal kaynaklara uyan akım (zunjingpai, 遵經派, ahl al-Sunnah) olarak anılmaktadır. Ayrıca Yihewani’ye, Çin İslam tarihinde geç dönemde çıktığ 1 için "yeni mezhep" de denilmektedir. ${ }^{56}$ Bunun nedeni onu, 1slah düşüncelerini benimsemeyen Müslümanların büyük kısmından (gedimu, 格底木) ayırmaktır. ${ }^{57}$

Yihewani sözcüğünden anlaşıldığ dünyasındaki gelişmelerden ilham almıştır. Yihewani'nin kurucusu Ma Wan-Fu (ö. 1352/1934) aslında Çin tarikatlarından birisinin bağlısıdır. 1886 yılında Ma, 4 sene süren hac seyahatine çıkmış ve hac sırasında İslam dünyasındaki âlimlerle iletişim kurmuştur. Ma'nın hacca gittiği zaman, tam da Vehhâbîlerin Osmanlılara karşı Arabistan'da devlet kurmaya ve Müslümanları aslî İslam'a döndürmeye çalıştığ1 dönemlere denk gelmektedir. Ayrıca Vehhâbîler, düşüncelerini yaymak amacıyla, Suûdilerle birlikte Bedevîleri dini milis kuvvetleri olarak teşkilatlandırmışlardır. Dolayısıyla o dönemde Vehhâbîlik Arabistan üzerine oldukça güçlü bir etkiye sahip olduğu için $\mathrm{Ma}$, ister istemez onların düşüncelerinden etkilenmiştir. ${ }^{58}$

Vehhâbî düşüncelerini benimseyen Ma Wan-Fu hacdan döndükten sonra “Kur'an'a dayanarak inancı kur (pingjing lijiao, 憑經立教)” ve “kutsal kaynaklara uy, İslam’a aykırı olan örfleri düzelt (zunjing gesu, 遵經革俗) sloganıyla Yihewani’yi kurmuş ve her şeyde Kur'an'a referans yapılması gerektiğini savunmuştur. Bunun üzerine Ma, tarikatların uygulama ve düşüncelerinin İslami prensiplerle çeliştiği ve dolayısıyla Müslümanları yanılttı̆̆ını kabul ettiği için, mensup olduğu tarikattan ayrılmış ve evliyalar, türbelere gösterilen saygıyı ve hocaların aşırı yetkilerini sert bir şekilde

56 Tong Ma, Çin İslamı'ndaki Mezhepler ve Tarikatların Özetlenmiş Tarihi (中國伊斯蘭教派與 門宦制度史略) (Yinchuan: Ningxia Renmin Chubanshe, 2000), 94.

57 Qing döneminde 1slah düşünceleri ortaya çıktıktan sonra Çinli Müslümanlar arasında farklılaşma başlamıştır. Genel olarak 1slah düşüncelerini benimseyen Müslümanlara “yeni mezhep (新教)”, ve Çin örfleriyle bütünleşmiş İslam’a uyan Müslümanlara “gedimu (格底木)” denilmektedir. Yeni mezhep genel bir terimdir. Onun kapsamında 1slah düşüncelerini benimseyen çeşitli Müslüman grupları bulunmaktadır. Gedimu Arapçada eski anlamına gelen "kadim"in transliterasyonunudur. Bu yüzden bu isimle "eski mezhep" kastedilmektedir. Gedimu'nun dini pratiklerinde Çin kültürü açık bir şekilde görülmektedir. Önemli derecede Konfüçyüsçü düşüncelerle bütünleşmiş olan Çin medrese eğitim sistemi, onlar arasında oldukça yaygındır. Bütün bunlar, Gedimu’yu yeni mezhebin sslah hareketinin ana hedefi kılmıştır. Bkz. Zhan-Fu Gao and Jun-Qing Min, “Mezhepler ve Çin Tarikatları (教派門宦),” in An Overview of Islam in China (中國伊斯蘭 教簡志), ed. Çin İslam Derneği (中國伊斯蘭教協會) (Beijing: Zongjiao Wenhua Chubanshe, 2013), 71-72. Yang \& Yu, İslam ile Çin Kültürü, 574-576.

58 Alexander Blair Stewart, Chinese Muslims and the Global Ummah: Islamic Revival and Ethnic Identity among the Hui og Qinghai Province (New York: Routledge, 2017), 37. 
eleştirmiştir. ${ }^{59}$ Ayrıca Sünnet ve Hanefîliğe sıkı bir şekilde uyarak İslam'ın beş şartına son derece önem vermiştir. Bu vurgu temelinde olmak üzere Ma, başka ayrıntılı konularda da düşüncelerini geliştirmiştir. O Çin'de yaygın bir şekilde rastlanan imamların cenazede para karşılığında Kur'an okumaları uygulamasını, Kur'an'1 Kerim'in para kazanmanın bir aleti olmaması gerektiği düşüncesiyle reddetmiştir. Müslümanların İslam'ın beş şartına odaklanmaları gerektiğine işaret ederek tatavvuları (nafileleri) yerine getirmeyi reddetmiştir. Peygamber Muhammed'in Resullulah olup Allah'nn bereketine zaten sahip olduğu için Mevlit Kandili’ni kutlamayı yasaklamıştır. Bütün bunlar içindeki en önemlisi ise Ma'nın, Çin tarikatlarında yaygın olan türbe ve evliya kültünü sert bir biçimde eleştirmiş olmasıdır. ${ }^{60}$ Özetle, bütün bu fikirlerin, kutsal kaynaklar ve tevhide yeniden vurgu yapan ve şirke karşı koyan girişim olduğunu söylemek mümkündür.

Düşünsel benzerliğine rağmen, Yihewani'nin, Vehhâbîliğin Çin versiyonu olduğunu söylemek pek doğru bir ifade olmayacaktır. Çünkü Yihewani'nin bazı mensupları kendilerini Vehhâbîler olarak kabul etmedikleri' ${ }^{61}$ gibi Yihewani'ler, Çinli Müslümanların çoğu gibi, Hanefîliğe bağlıdır. Bu, yukarıda Yihewani’nin düşüncelerinde kolaylıkla görülmekte ve Hanbelîliğe bağlanan Vehhabilerden farklılaşmaktadır. İkinci olarak Yihewani, Çin İslamı'nın bir parçası olarak konumu içinde geliştiği ortam tarafından etkilenmiştir. Çin'deki Müslümanlar her zaman azınlık konumunda ve mütevazı bir yere sahip oldukları için, Ma'nın ileri sürdüğü prensipler arasında gayrimüslimlerle ilişkiyle ilgili fikirler neredeyse bulunmamaktadır. Öte yandan, Muhammed b. Abdülvehhâb (ö. 1206/1792) gayrimüslimlerin niteliğini tanımış ve Müslümanların onlar arasında yaşamalarını, dini pratikleri serbestçe yerine getirmeleri ön şartıyla onaylamıştır. ${ }^{62}$ Son olarak Yihwan, Vehhâbîlik gibi devlet ideolojisi olmamıştır. Daha doğrusu o, dini reformla sınırlı kalmış ve siyasi bir iddiaya sahip olmamıştır. Gerçi Çin Cumhuriyet dönemine girdiğinde, kuzeybatı bölgelerinde kurulan yönetimin başındaki Müslüman bir yönetici olan Ma Bu-Fang (ö. 1395/1975) Yihewani’nin düşüncelerini kullanarak ötekilerini kâfir olarak bastırmaya ve dolayısıyla siyaset arenasında bir takım

59 Dru C. Gladney, "Islam in China: Accommodation or Separation?" in Religion in China, Major Concepts and Minority Positions, eds. Max Deeg \& Bernhard Scheid, (Vienna: Austrian Academy of Sciences Press, 2015), 216.

60 Yang \& Ma, İslam Uzun Vadeli Muhteşemdir, 140. Yang \& Yu, İslam ile Çin Kültürü, 589. Ma, Çin Íslamı'ndaki Mezhepler ve Tarikatların Menşeii Incelemesi, 138-139.

61 Ma, Çin İslamı'ndaki Mezhepler ve Tarikatların Menşeii İncelemesi, 144.

62 Natana J. Delong-Bas, "Wahhabism and the Question of Religious Tolerance," in Religion and Politics in Saudi Arabia: Wahhabism and the State, eds. Mohammed Ayoob and Hasan Kosebalaban, (London: Lynne Rienner Publisher, 2009), 13-14. 
menfaatler elde etmeye çalışmıştır, ${ }^{63}$ fakat bu girişim yalnızca Müslümanların yoğun yaşadıkları bölgelerde başarılı olabilmiştir. Ayrıca Ma Bu-fang sadece seferberlik durumunda Yihwan'dan faydalanabilmiştir. Çünkü Ma Wan-Fu kendisi siyasi veya fıkhi bir düşünce sistemi kurmamıştır. Vehhâbîlik ise 1744 yılından günümüze kadar Suudi Arabistan'ın siyasi ideolojisi olarak tanınmaktadır. Kral Muhammed b. Suûd (ö. 1179/1765) merkezi hükümet kurduktan sonra Vehâbbî pratiklerini yürürlüğe koymuştur. ${ }^{64}$ Ve günümüzdeki Vehhâbîlik Arabistan hükümetinin siyasi gücünü sağlamlaştırmak için kullanılmaktadır. ${ }^{65}$

Yihewani ile Vehhâbîlik arasındaki benzerlik ve farklılık, İslami ıslah hareketinin çeşitli toplumsal bağlamlara göre değiştiğine işaret etmektedir. Ma Wan-Fu muhtemelen Vehhâbîlikten ilham almış, fakat onu olduğu gibi Çin'e taşımamıştır. Memleketindeki durumlar için faydalı olduğunu düşündüğü Vehhâbî düşüncelerinden seçmiştir. Onun ana hedefi Çinli Müslümanları yanıltıcı inançlardan kurtarmak için, dini reforma odaklanmak olmuştur. Düşüncelerinde gayrimüslimlerle veya siyasi güçlerle ilişkiler ikinci plandadır. Ayrıca, Çin'in siyasi statükosu da Yihewani'nin Vehhâbîlik kadar güç kazanmasına izin vermez. Bu da Çinli Müslümanların tarih boyunca daima azınlık konumunda olmalarından kaynaklanmaktadır. Bununla birlikte Yihewani’nin etkisi günümüzün Çin'inde, özellikle kuzeybatı bölgelerinde olmak üzere hâlâ görülmektedir. Bu bakımdan Yihewani'nin Çinli Müslümanların dini kimliğini muhafaza etmelerine katkıda bulunduğunu söylemek mümkündür.

\section{Yihewani'nin Bölünüşü: Saileifengye'in (Selefîlik, 賽萊費耶) Ortaya Çıkışı}

Yihewani'ler arasında 1930'larda bölünme yaşanmış ve Sailaifengye olarak anılan bir kısım Yihewani'den ayrılmıştır. Sailaifengye'nin, telaffuzundaki benzerlikten anlaşılacağ 1 üzere, Arapça Selefiyye'nin transliterasyonu olup onunla İslam tarihinin ilk üç nesli kastedilmektedir. Bu grup namaz kılarken üç defa tekbir almaktadır bundan dolayı da Çinli Mülümanlar onları Yihewani' den ayırtetmek için 'üç tekbir mezhebi (santaipai, 三抬派)" olarak adlandırmışlardır. ${ }^{66}$

Aslında Sailaifengye'in kurucusu Ma De-Bao (ö. 1397/1977) Yihewani'nin ünlü imamları arasında yer almaktaydı. Ma, 1936 yılında hacca gitmiştir. O dönem Suudi Arabistan'ın kurucusu Abdülazîz b. Suûd (ö. 1373/1953) iktidardaydı.

63 Stewart, Chinese Muslims and the Global Ummah, 38.

64 John S. Habib, "Wahhabi Origins of the Contemporary Saudi State," in Ayoob and Kosebalaban, Religion and Politics in Saudi Arabia, 58.

65 Bkz. Gwenn Okruhlik, "State Power, Religious Privilege, and Myths About Political Reform," in Ayoob and Kosebalaban, Religion and Politics in Saudi Arabia, 58.

66 Ma, Çin İslamı'ndaki Mezhepler ve Tarikatların Özetlenmiş Tarihi, 107. 
Uluslararası arenayı iyi tanıyan İbn Suûd, yeni kurulan devletin ayakta kalabilmesi için, gayrimüslimlere karşı sert bir tavır takınan radikal Vehhâbîliği kontrol altına almak gerektiğinin farkına varmıştır. ${ }^{67}$ Bunun üzerine, siyaset, eğitim, teknoloji ve din gibi çeşitli alanlarda Vehhâbîlerle mücadeleye başlamıştır. Sonuç olarak, Vehhâbîlik İbn Suûd'un iktidar döneminde daha 1lımlı bir hal almıştır. Küfre bulaşmayan yerli örfler, tarikatlar hatta Şiîliğe tolerans gösterilmiştir. ${ }^{68} \mathrm{Bu}$ dönemde Arabistan'a varan Ma, muhtemelen Vehhâbbîliğin 1lımlı versiyonu tarafından etkilenmiştir. Çin'e döndügünnde kendi görüşlerini ileri sürmüş ve dolayısıyla Yihewani'den ayrışmıştır.

Sailaifengye kısmen Yihewani'nin düşüncelerini ve konumunu devam ettirmektedir. Bu, İslam'ın beş şartına sıkı sıkıya bağlanma, tarikatların İslam'a aykırı uygulamaları ve türbe kültüne karşı çıkma, Kur'an'ı paralı olarak okumayı reddetme ve tütsü kullanma gibi hususlarda kolaylıkla görülmektedir. Ancak bazı konularda ikisi birbirlerinden oldukça farklıdır. Sailaifengyeler, İslam dünyasındaki birçok selefi hareketlerinde görüldüğü gibi, mezhepleri tarih olaylarının bir ürünü olarak düşünmektedir. Bu yüzden onlar belli bir mezhebe bağlanmamakta ve Müslümanların doğrudan kutsal kaynaklar üzerinde düşünmeleri gerektiğini savunmaktadırlar. Bu nedenle Sailaifengye'ler, Hanefîliğe sıkı bir şekilde bağlanan Yihewani'yi, İslam dünyasının gelişmesini engellediğini düşündüklerinden taklitçi olarak kınamışlardır. ${ }^{69}$ Bunun, selefîlikte sık sık gündeme gelen içtihat ve taklit karşıtlığıyla aynı olduğunu söylemek mümkündür. Aynı şekilde fikıh konusunda Sailaifengye'ler, mezheplerin farklı1ıklarını atlayarak doğrudan sahabe ve tâbiînin icmâs1 ve görüşlerine müracaat etmektedirler. Bu da, Sailaifengye'de içtihada ne kadar önem verildiğini göstermektedir. Kutsal kaynaklarla ilgili olarak, Sailaifengye'ler Müslümanların Kur'an ayetlerinin literal anlamına sadık kalmaları gerektiğini önemle savunmaktadır. Onlara göre, bazı ayetlerin anlamının anlaşılmadığı halde açıklanmaya çalışılması kabul edilmemelidir. Zira insan aklıyla ulaşılan sonuç Müslümanları yanıltabilir. Bu yüzden Sailaifengye'ler Yihewani’yle birçok konuda tartışmaya girmişlerdir. ${ }^{70}$ İçtihat ile kutsal kaynakların literal anlamını savunması itibarıyla Saifaifeiye'yi Selefî lafcı (literalist) olarak nitelendirmek mümkündür. ${ }^{71}$ Son olarak yukarıda sözü geçen namaz kılınışı başta olmak üzere, imamla namaz

67 David Commins, The Wahhabi Mission and Saudi Arabia (New York: Palgrave Macmillan, 2009), 71-72.

68 Commins, The Wahhabi Mission and Saudi Arabia, 78-80.

69 Ma, Çin İslami ’ndaki Mezhepler ve Tarikatların Özetlenmiş Tarihi, 110.

70 Allah'ın kâinatta bulunduğu yer, O'nun uzvu gerçeği ve O'nun arş üzerine oturması gibi konular tartışmalar arasında yer almaktadır. Stewart, Chinese Muslims and the Global Ummah, 38.

71 Tariq Ramadan, Western Muslims and the Future of Islam (New York: Oxford University Press, 2004), 25. 
k1larken Fatiha'yı sesli veya sessiz okuma, namazdan sonra dua ve sünnet namazının sıras1, mezarlıkta Kur'an'ın okunup okunmaması ve teravih'in sayısı gibi şeyler Sailaifengye ile Yihewani birbirlerinden farklılaştıran meseleler arasında yer alır. ${ }^{72}$

İslam dünyasındaki Selefîlik, Orta Çağdan günümüze kadar farklı şekiller almış ve çeşitli içerikler ihtiva etmiştir. Nitekim Selefîliğin birçok alt kategorisi bulunmaktadır. Kimi selefîler siyasetin reformun tek yolu olduğunu düşünürken, kimileri sosyal ve eğitimle ilgili reformlara odaklanmaktadırlar. Bununla birlikte, Sailaifengye'nin, kutsal kaynaklara dönmek, içtihadın uygulanmasını ve katıksız bir monoteizm İslam'ını savunmak itibarıyla, Selefî hareketlerle aynı çizgide olduğu şüphesizdir. Ayrıca bazı Sailaifengye'ler, Vehhâbîlikten ilham almasına rağmen, kendisini Vehhâbîlerle ilişkilendirmeyi reddetmektedirler. Onlara göre bu, önceki dönemde vefat eden âlimlerden birisini takip etmek anlamına gelmekte ve dolayısıyla selefî konumuyla çelişmektedir. ${ }^{73}$ Bu örnekten Sailaifengye'nin selefîliğe ne kadar sıkı bağlandığı kolaylıkla anlaşılmaktadır. Bütün bunlar, Salaifieye'nin Yihewani'den daha çok İslam dünyasına yaklaştığını göstermektedir.

\section{Değerlendirme ve Sonuç}

Müslümanların Çin kültürünü kabul etmeleri, İslami düşüncelerin Konfüçyüsçülükle bütünleşmesi ve İslami ihya ve 1slah hareketlerinin ortaya çıkışı, İslam'ın Çin de asırlarca ayakta kalabilmesinin önemli unsurları arasında sayılabilir. Bunlardan anlaşıldığı üzere İslam ve Çin kültürü arasında genel olarak çatışma değil, alışverişe benzer bir ilişki bulunmaktadır. Bu ilişkinin sonucunda iki kültürün özelliklerini bir araya getiren Çin İslamı ortaya çıkmıştır. Yerelleşme ve küreselleşmenin, İslam'ın Çin'deki varlığının devam ettirmesi ve gelişmesinde oldukça önemli bir rol oynadığı söylenebilir.

Çin medrese eğitim sisteminin kuruluşu ve Çince dini kitapları yazma şeklindeki girişimleri kapsayan yerelleşmenin iki anlamı vardır. Birincisi, Çinli Müslümanların kendi inançlarını yeniden göz önünde bulundurmaları ve dolayısıyla dini şuuru tekrar uyandırmalarıdır. İkincisi, İslam'ın Çin kültürüyle bütünleşmesi ve dolayısıyla Çin İslamı'nın ortaya çıkmasıdır. Bu ikisi karşılıklı olarak değerlendirilmelidir. Yerelleşme süreci, her zaman Müslüman topluluk içi-dışı, Çin kültürü-İslam kültürü ve imanküfür şeklindeki iki tarafın etkileşimiyle işlemektedir. Bu ikilikler arasında bir çatışmanın bulunması zorunlu değildir. Sözü geçen iki girişimde görüldüğü üzere, Çinli âlimler bir yandan Konfüçyüsçülüğe sarılmışlar, öte yandan İslam prensiplerinde ısrar etmişlerdir. Onların hedefi Müslümanların kendi dinlerini devam ettirerek Çin

72 Stewart, Chinese Muslims and the Global Ummah, 43.

73 Stewart, Chinese Muslims and the Global Ummah, 42. 
toplumuyla bütünleşmeleridir. Bu çabaları sayesinde İslami esaslar tekrar ön plana çıkmış ve Çin toplumu da İslam'la bütünleşmiştir. Bu bakımdan İslam'ın yerelleşmesi, Müslümanların hem yeniden "İslamileştirilmeleri”ne hem de "Çinlileştirilmeleri”ne katkıda bulunmaktadır. Bunu diyalektik bir süreç ve Çin İslamı'nın ise bu diyalektik süreç sonucunda ortaya çıkan sentez olduğunu düşünmek mümkündür.

Bu sürecin diyalektik niteliği, Çinli âlimlerin girişimlerinden kolaylıkla anlaşılmaktadır. Onlar Konfüçyüsçü düşüncelerle İslam'ı açıklamalarına rağmen, Çin kültürü ve İslam arasındaki sınırı titiz bir şekilde tanımlamış ve bu sınırı korumaya çalışmışlardır. Wang Dai-Yu, Müslümanların Çin imparatorlarına sadakatini tevhit temelinde kurmuştur. Ona göre, biri ancak tevhidi anladıktan sonra yüreği dosdoğru olabilir (xinzheng, 心正); yüreği dosdoğru olduktan sonra, imparatorlara gerçek sadakate (zhenzhong, 真忠) ulaşabilir. Wang, böylelikle Müslümanların tanrısal bir nitelik taşıyan Çin imparatorlarına sadakat konusunda yaşadıkları gerginliği hafifletmeye çalışmıştır. ${ }^{74}$ Aynı şekilde, Ma De-Xin İslam ile Konfüçyüsçülük arasındaki farklılıkları fark edip Allah'ın dünyayı yaratışı, ahiret ve tevhit gibi kavramları yeniden ileri sürmüştür. Bütün bunlar İslam'ın düşünsel yerelleşmesinin, felsefi düzlemle sınırlı kaldığını göstermektedir. Düşünsel süreç bu sınırı aştığında, Çinli âlimler hemen uyararak durumu düzeltmeye çalışırlar. Bu yüzden İslam'ın, esasına ve prensiplerine dokunmaksızın Çin'de yerelleştiğini söylemek mümkündür.

Çinli âlimlerin çabalarına rağmen, İslam Çin kültürü tarafından ister istemez etkilenmiştir. Bu etki sebebiyle, İslam dünyasından gelen esinler, Çin'de ihya ve ıslah hareketlerine yol açmıştır. Bu esinlere, yukarıda sözü geçen Yihewani ve Sailaifengye başta olmak üzere, 20. yüzyılın son çeyreğinde Hindistan'dan gelen Tebliğ Cemaati örnek olarak verilebilir. Vehhâbîlik ve Diyobendi düşünceleri gibi İslami 1slah mesajları önemli bir ölçüde küreselleşmiştir. Bu da, dünyanın her bölgesinde bulunan Müslümanlara kendi dinini yeniden sorgulama firsatını sunmuştur. Çin örneğinde Yihewani ve Sailaifieye'nin Vehhâbî düşünceleriyle tarikatların batıl inançları ve Çinli Müslümanların bazı dini pratiklerini eleştirerek ihya ve ıslah hareketini başlatmalarını bu bağlamda değerlendirmek gerekir.

Burada dikkat edilmesi gereken bir diğer husus, küreselleşmenin bir açıdan aynı zamanda yerelleşme olmasıdır. Yihewani ve Sailaifengye açıkça Vehhâbîlikten ilham aldığı halde, onu olduğu gibi Çinli Müslümanlara uygulamamıştır. İkisi daha çok Vehhâbîlerin dini pratiklerindeki İslami olmayan bid'atları arındırma düşüncelerini benimsemiştir. Ayrıca yukarıda değinildiği gibi, Yihewani ve Sailaifengye’nin dini

74 Ding Jun, “Gerçek Sadakatın Doğru Yolu ile Orta Yol: İslam Doktrini ile Konfüçyüsçü Düşüncelerinin Diyalogu (真忠正道與中庸之道: 伊斯蘭教義與儒家思想之對話), ” in Lin, Localization of Islam in China, 56. 
pratiklerin ayrıntıları hususunda farklılaşmalarının, onların tamamen Çin İslamı'nı sslah etmeye odaklandığına ve dolayısıyla Vehhâbîler gibi siyasi bir ideoloji geliştirmediğine işaret ettiğini söylemek gerekir. Bunun nedenlerinden en önemlisi, Ma Wan-Fu ve Ma De-Bao'nun aldıkları 1slah düşüncelerini değiştirerek bunları kendi hareketlerinde Çin İslamı'nın bağlamına uyarlamal çabalarıdır. Bu anlamda İslam dünyasında ortaya çıkan bir akım, dünya çapında yayılmak istediğinde, farklı bölgelerin şartlarına göre yerelleşmek zorundadır.

Son olarak, Çin İslamı örneğinde, İslam'ın yerelleşmesi ve küreselleşmesinin, onun varlığında hayati bir rol oynadığını söylemek yerinde olacaktır. Bir yandan yerelleşmesi İslam'1 Çin toplumu ve kültürüyle bütünleştirerek gayrimüslim bir ortamda varllğını sürdürmesine imkân sağlarken, öte yandan küreselleşmesi yani İslam dünyasıyla bağını devam ettirmesi, İslam'ın Çinlileşmesini bir dereceye kadar durdurmuş ve dolayısıyla tamamen Çin kültürüne asimile olmasını engellemiştir. Bu yüzden, Çin İslam tarihinin, bu iki sürecin birbirleriyle etkileşiminden oluştuğunu düşünmek mümkündür.

Hakem Değerlendirmesi: Dış bağımsız.

Çıkar Çatışması: Yazar çıkar çatışması bildirmemiştir.

Finansal Destek: Yazar bu çalışma için finansal destek almadığını beyan etmiştir.

Peer-review: Externally peer-reviewed.

Conflict of Interest: The author has no conflict of interest to declare.

Grant Support: The author declared that this study has received no financial support.

\section{Kaynakça/References}

Ayoob, Mohammed, and Hasan Kosebalaban, eds. Religion and Politics in Saudi Arabia: Wahhabism and the State, London: Lynne Rienner Publisher, 2009.

Bai, Shou-Yi. Çin İslamı'nın Küçük Tarihi (中國回教小史). Ningxia: Ningxia Renmin Chubanshe, 2000.

Bao, Xiu-Ping. “Çin İslam Derneğinin Kuruluşu ve Gelişmeleri (中國回教協會的創建及其發展).” in Allah'ın Emirlerinin Nesilden Nesle Geçişi ve Devamlılı̆̆ı: İslam'in Tayvan'daki Yayılması ve Öngörmeleri (主命的傳承與延續: 回教在台灣的發揚和展望), edited by Xi-Lin Zhao ve Zhong-Fu Zhang, Taipei: Chengchi University Press, 2019, 53-92.

Benite, Zvi Ben-Dor. The Dao of Muhammad: A Cultural History of Muslims in Late Imperial China. Cambridge \& London: The Havard University Asia Center, 2005.

Bilinmeyen yazar. Ming Tai Zu Imparatorunun Gerçek Kaydl (1) \& (4) (明太祖實錄卷一、卷四). Taipei: Institute of History and Philology, Academia Sinica, 1968.

Chang, Hajji Yusuf. "The Hui (Muslim) Minority in China: An Historical Overview." In Islam in China: Key Papers, edited by Michael Dillon, Folkstone: Global Oriental, 2009, 132-147. 
Commins, David. The Wahhabi Mission and Saudi Arabia. New York: Palgrave Macmillan, 2009

Çifçi, Esra. “Çin'de İlk İslami Entelektüel Çaba ve Konfüçyanist Müslümanlar (Hui-Ru),” II. Türkiye Lisansüstü Çalışmalar Kongresi Bildiriler Kitabı - IV. 6-8 Mayıs 2013, Bursa, 865-878.

Çifçi, Esra. "Han Kitap.” TDV İslam Ansiklopedisi. https://islamansiklopedisi.org.tr/han-kitap.

Çin Felsefe Kitapları Elektronikleştirme Projesi. “Ming Hanedanlığının Kanun Kılavuz cilt 6 (大明 律集解附例卷之六).” http://ctext.org/wiki.pl?if=gb\&chapter=466350.

Dillon, Michael. China's Muslim Hui Community: Migration, Settlement and Sects. Richmond Surrey: Curzon Press, 1999.

Ding, Cheng-Long. “İslam Dünyasının Ayinlerinin Son Sözü (天方典禮咙)”, Liu Zhi, İslam Dünyasının Ayinleri (天方典禮), edited by Jia-Bin Zhang, \& Yong-Hao Du, Tianjin: Tianjin Guji Chubanshe, 1988, 229-236.

Frankel, James D.. Rectifying God's Name: Liu Zhi's Cofucian Translation of Monotheism and Islamic Law. Hawai'i: University of Hawai'i Press, 2011.

Fu, Tong-Xian. Çin İslam Tarihi (中國回教史). Taipei: Taiwan Shangwu Yinshuguan, 1996.

Gao, Zhan-Fu, Jun-Qing Min, “Mezhepler ve Tasavvuf Grupları (教派門宦).” In An Overview of İslam in China (中國伊斯蘭教簡志), edited by Çin İslam Derneği (中國伊斯蘭教協會), Beijing: Zongjiao Wenhua Chubanshe, 2013, 71-81.

Gladney, Dru C. "Islam in China: Accommodation or Separation?" in Religion in China, Major Concepts and Minority Positions, edited by Max Deeg \& Bernhard Scheid, Vienna: Austrian Academy of Sciences Press, 2015, 187-228.

Gladney, Dru C. Muslim Chinese: Ethnic Nationalism in the Peopel's Republic of China. Cambridge: Havard University Council on East Asian Studies, 1991.

Gu, Yu-Jun. Ming ve Qing Hanedanlı̆̆ Dönemlerinde Hui Etnik Grubunun Ĕgitimi ve Düşünceleri Araştırmaları (明清時期回族教育思想研究), yayımlanmamış doktora tezi, Beijing: Minzu University of China, 2012.

Ha, Bao-Yu Ha. “Medrese Eğitiminin Mevcut Durumu ve Sorunlar1 Mütalaas1 I (經堂教育現狀 及存在問題的調查研究(上)), "Studies in World Religions(世界宗教研究), 6(2018): 176-187.

Hu, Si-Yuan. Kadiriyah: The Spreading and Variation of A Western Sufi Order in China (嘎迪林 耶: 一個西域蘇菲教團的在華傳播與變異). yayımlanmamıs yüksek lisans tezi, Guangzhou: Jinan University, 2016.

Israeli, Raphael. Islam in China: Religion, Ethnicity, Culture, and Politics. Oxford: Lexintong Books, 2002.

Jin, Yi-Jiu. Çin İslamı'nın Gizeminin Keşfi: Liu Zhi İncelemesi (中國伊斯蘭探秘: 劉智研究). Beijing: Zhongguo Renmin Daxue Chubanshe, 2010.

Jin, Yi-Jiu Jin. Sufism in China (蘇菲主義在中國). Beijing: Social Sciences Academic Press, 2013.

Jin, Yi-Jiu. Wang Fai-Yu’nun Düşüncelerinin Incelenmesi (王岱輿思想研究). Beijing: Minzu Chubanshe, 2008.

Lin, Chang-Kuan. "Çin Cumhuriyeti’ndeki İslam: Çağdaş Çince Konuşan Müslüman Topluluğun Gelişmeleri İncelemesi (中華民國伊斯蘭: 當代漢語穆斯林社群發展之解析),”Cross-Cultural Studies (文化越界) 11(Mart, 2014): 113-150.

Lin, Chang-Kuan. Çin Íslam'ının Gelişmeleri ve Hareketleri (中國回教之發展及其運動). Taipei: Zhonghua Mingguo Alabo Wenhua Jingji Xiehui, 1996. 
Lin, Chang-Kuan, ed. Localization of Islam in China (伊斯蘭在地化: 中國伊斯蘭發展之探討). Hong Kong: The Research Institute for the Humanities, The Chinese University of Hong Kong, 2015.

Maerjiang, Wu. "Klasik İslam Eserlerinin Çince’ye Tercüme Faaliyetlerinin Çin'de İslamiyet'in Gelişimine Katkısı," Edebali İslamiyat Dergisi 2/4 (Kasım 2018): 53-81.

Ma, Ming-Dao. Ming Kraliyet Ailesinin Inancının Ilk Tahlili (明朝皇室信仰考初稿). Taipei: Zhongguo Huijiao Wenhua Jijinhui, 1984.

Ma, Qi-cheng, and Hong Ding. Çin İslamı'nın Kültürü Kategorisi ve Etnik Özellikleri (中國伊斯蘭 文化類型與民族特色). Beijing: Zhongyang Minzu Daxue Chubanshe, 1991.

Ma, Qiang. "Field Investigation and Thing on the Hui and Islamic Cultural Education (回族伊斯 蘭文化教育的田野調查及思考).” Researches on the Hui (回族研究) 52/4 (2003): 104-110.

Ma, Tong. Çin İslamı'ndaki Mezhepler ve Tarikatların Menşeine Dair Bir Inceleme (中國伊斯蘭 教派門宦溯源). Yinchuan: Ningxia Renmin Chubanshe, 2000.

Ma, Tong. Çin İslamı'ndaki Mezhepler ve Tarikatların Özetlenmiş Tarihi (中國伊斯蘭教派與門宦 制度史略). Yinchuan: Ningxia Renmin Chubanshe, 2000).

Mi, Shou-Jiang, and Jia You. Çin İslamı'nın Kısa Tarihi (中國伊斯蘭教簡史). Beijing: Zongjiao Wenhua Chubanshe, 2000.

Qiu, Shu-Sen ed., Çin'deki Hui Etnik Grubu Tarihi (中國回族史). Ningxia: Xingxia Renmin Chubanshe, 1996.

Ramadan, Tariq. Western Muslims and the Future of Islam. New York: Oxford University Press, 2004.

Shi, Ke-Zong. “İslam'la İlgili Kuşkuların Çözümlenmesi’nin Ön Sözü (清真釋疑序).” aktarılan Zhan-Ming Ma, İslam 'la İlgili Kuşkuların Çözümlenmesi Incelemesi (清真釋疑研究), Beijing: Zhongguo Shehui Kexue Chubanshe, 2013, 64.

Stewart, Alexander Blair. Chinese Muslims and the Global Ummah: Islamic Revival and Ethnic Identity among the Hui of Qinghai Province. New York: Routledge, 2017.

Tie, Guo-Xi. “Çin İslamı Eğitimine Giriş (淺論中國伊斯蘭教教育).” Researches on the Hui (回 族研究) 45/1 (2002):70-74.

Ünal, Elvida. “Çin Tarzı İslam: Konfüçyanist Müslümanlı (Hui-Ru).” TYB Akademi 20 (Eylül 2017). http://www.tyb.org.tr/elvida-unal-cin-tarzi-islam-konfucyanist-muslumanlik-hui-ru-31491h.htm.

Wang, Jun-Rong. “Tasavvuf Düşünceleri ve Çin Felsefesi: Tasavvuf Eserlerinin Çin'deki Çevirileri ve anlamları Tartışmas1 (蘇菲思想與中國哲學: 談蘇菲著作在中國的翻譯和意義), ’ Researches on the Hui (回族研究) 87/3(2012): 17-23.

Wang, Ling-Gui. Çin İslam Tarihi (中國伊斯蘭教史). Beijing: Zhongguo Youyi Chuban Gongsi, 2014.

Yang, Gui-Ping, and Xiao-Ying Ma. İslam Uzun Vadeli Muhteşemdir: Çin İslamı (清真長明: 中國 伊斯蘭教). Beijing: Zongjiao Wenhua Chubanshe, 2007.

Yang, Gui-Ping. “Ma De-Xin’s Da Hua Thoughts (馬德新的大化思想).” Researches on the Hui (回族研究) 51/3 (2003):66-70.

Yang, Huai-Zhong, and Zhen-Gui Yu. Islam ile Çin Kültürü (伊斯蘭與中國文化). Ningxia: Ningxia Renmin Chubanshe, 1996.

Yibulaheimai, A. “Hui Etnik Grubundaki “Xiaojing”in Karakter Sistemi Incelemesi (回族”消經”文 字體系研究), " Etnik Diller ve Yazular (民族語文) 1(1992): 25-32.

Yu, Zhen-Gui. Çin Hanedanlıkları ve İslam (中國歷代政權與伊斯蘭教). Yinchuan: Ningxia Renmin Chubanshe, 1996. 